\title{
A Simplified Ground Thermal Response Model for Analyzing Solar-Assisted Ground Source Heat Pump Systems
}




\section{Abstract}

19 Ground source heat pump systems that are installed in areas with heating or cooling dominant

20 seasons, or in buildings with utilization characteristics that lead to a disparity in demand, often

21 encounter challenges related to ground thermal imbalance. This imbalance can lead to long-term

22 ground temperature changes and may cause premature system failure. This paper focuses on

23 combining a ground source heat pump system with a solar thermal array, with the goal of

24 eliminating the effect of ground thermal imbalance, and minimizing system lifetime cost. A

25 thermal mass ground heat transfer model is combined with a time-stepping model to analyze the

26 system for a variety of solar array sizes. The details associated with this modelling technique are

27 presented, and case studies are provided to illustrate the results of the calculations for three

28 different buildings. It is shown that increasing the solar array size can offset ground thermal

29 imbalances, but increasing the array size also results in a larger initial system cost. An economic

30 analysis is then carried out to determine the system lifetime cost as a function of this solar array

31 size, and an optimal array size from an economic perspective was found. The result of the study

32 shows that hybridizing a ground source heat pump system with a solar array produces a viable

33 system from a technical and economic standpoint, can be used to avoid premature system failure,

34 and can reduce system lifetime cost. 


\section{$37 \quad$ 1. Introduction}

\section{$39 \quad 1.1 \quad$ Research Motivation}

41 As global concerns with respect to climate change increase, there is growing pressure on building 42 system designers to reduce energy consumption by improving system efficiency. There are a wide

43 variety of efficiency improvements that can be implemented, ranging from new system hardware

44 to sophisticated building control, but the target is typically to reduce building energy demand, and

45 therefore energy cost. This reduction in energy demand often results in a decrease of greenhouse 46 gas emissions from burning fossil fuels for heating a building, which is also being more heavily

47 mandated by new emission laws in many jurisdictions. Ground source heat pump (GSHP) systems

48 are being implemented as one of these efficiency measures since they can be designed to operate

49 without on-site fossil fuel use, and can offer stable system efficiency year-round when compared

50 to air source heat pumps [1].

52 The design of GSHP systems in heating or cooling dominant climate-zones, or for buildings with

53 utilization characteristics that lead to a disparity in demand, often encounter challenges due to

54 annual building load imbalances. These imbalances can cause long-term ground temperature

55 changes from heat accumulation or depletion in the ground, which can lead to premature system

56 failure [2]. To offset these imbalances, a geo-exchange system can be hybridized with conventional

57 heating or cooling systems, such as natural gas boilers, such that the annual net ground heat

58 exchange does not cause premature system failure [3] [4]. However, using fossil fuels for

59 hybridization still results in direct $\mathrm{CO}_{2}$ emissions from the system, and may not be sustainable for

60 long-term use. Therefore, there is now focus on using renewable energy for GSHP hybridization, 
61 and much of this focus is on the use of solar thermal panels since they can provide efficiencies of

62 approximately $60 \%$ and emission-free heat at temperatures ranging from approximately $5^{\circ} \mathrm{C}$ to

$6360^{\circ} \mathrm{C}$ depending on weather conditions and panel selection [5]. In these systems, the interactions

64 between the ground, heat pump, and solar array are critical to determine system performance, but

65 these interactions are not well understood.

66

67 This paper focuses on the techno-economic analysis of a GSHP system that is hybridized with a 68 solar thermal array, such that ground thermal-imbalance can be mitigated, and the lifetime cost of

69 the system can be minimized. Unlike other studies in the literature, this analysis utilizes a 70 conduction heat transfer finite element ground model to determine the effect of thermal loads on 71 the ground. A finite element model simplification technique based on a thermal mass model is also

72 presented, which allows for a reduction in computation times, while still delivering results within

$735 \%$ of those from a detailed finite element model. Manufacturer heat pump performance data,

74 along with a semi-empirical solar energy analysis, are used alongside this simplified model to 75 predict overall system performance.

\subsection{Existing Solar-assisted Ground Source Heat Pump Systems, and Modelling Methodologies}

80 The use of solar energy as a replacement for conventional heat sources is increasing in popularity

81 due to concerns over fossil fuel usage and greenhouse gas (GHG) emissions [6] [7]. Some systems

82 use the solar thermal array as a refrigerant evaporator [8] [9], while others circulate water or a

83 water-antifreeze mixture through the solar panel to extract sensible heat [10] [11]. Systems may

84 also implement a thermal energy storage (TES) tank, which is used to store heated water before 
85 circulating the water to the ground or the building [7] [12]. A statistical analysis of these studies

86 has found that the addition of solar energy to the GSHP system can improve overall system

87 efficiency by $10 \%$ to $20 \%$ in balanced systems, which will be used for comparison with the results

88 of this study to ensure the reliability of the findings.

90 In this study, while improved system efficiency is a valuable result of using solar energy, the

91 primary motivation for adding a solar array to the GSHP system is to replenish the thermal energy

92 removed from the ground during winter months. The use of solar energy for this reason in an air-

93 based thermosiphon system, coupled with a GSHP, has been shown to negate the effects of

94 imbalanced thermal loads [13]. A flat-plate liquid solar panel system with TES was investigated

95 for use in cold-climates, to reduce ground thermal imbalance, and the long-term efficiency of the

96 system was shown to be stable [14]. Another study investigated the effect of adding a solar array

97 to a three-year-old GSHP system, and it was shown that initial ground temperature decreases of

$980.2^{\circ} \mathrm{C}$ per year can be reversed by the solar thermal energy [15]. However, these studies did not

99 implement a detailed ground temperature model to predict long-term ground temperature changes.

100

101 Ground thermal models in the literature are typically categorized as either analytical or numerical,

102 and are often used to predict long-term temperature changes of the ground [16]. Analytical models

103 include the infinite line-source model, along with the cylindrical source model, and both of these

104 models neglect vertical heat transfer [17] [18]. The resistance-capacitance approach to ground

105 modelling is based upon an electrical circuit analogy, and can account for the interaction between

106 the U-tube, grout, and the ground [19]. Finite element models have also been developed, and a

107 two-dimensional model that accounts for one plane along the borehole depth has been shown to 
108 estimate borehole heat transfer within $8 \%$ of experimental values [20]. Finite element modelling

109 has also been carried out using three-dimensional models, which allow for prediction of variable

110 fluid temperatures along the borehole, and can also account for fluid flow dynamics in the borehole

111 pipe [16] [21]. However, in an on-off flowrate GSHP system, calculation of the fluid flow

112 characteristics is not necessary and a three-dimensional numerical model that uses a heat flux term

113 to represent the thermal load of the fluid on the ground has been validated against experimental 114 data [22].

115

116 The work in this paper builds upon the previous solar-assisted GSHP studies by using a finite

117 element ground model to predict the thermal response of the ground as a function of the solar118 assisted GSHP system loads, and uses this response to determine system performance.

$120 \quad 1.3 \quad$ Detailed Finite Element Ground Model

122 In this study, a conduction heat transfer finite element model was used to determine ground 123 temperatures in the GSHP system, as a function of the ground loads over time. This model was 124 based upon the work completed by Law and Dworkin [22], with the modelling done using 125 COMSOL [23]. The geometry shown in Figure 1 illustrates the dimensions and boundary 126 conditions that were applied when using this technique. 

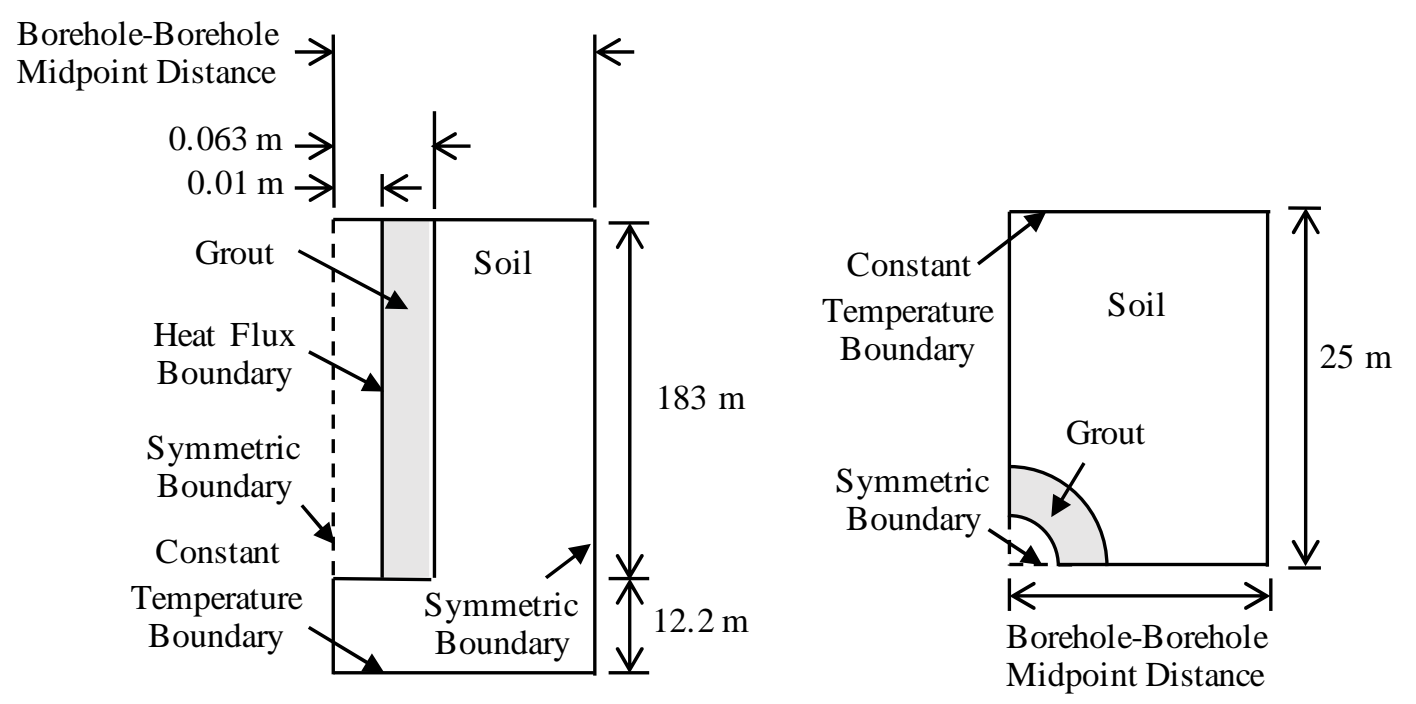

132 A single borehole from a multiple borehole GSHP system is included in the model, and symmetry 133 conditions along mesh boundaries are used to replicate the effects of additional boreholes. Heat

134 transfer in/out of the ground is included using a heat flux, which is applied along the boundary that 135 represented the outside of the fluid-carrying pipe that is encased within a grout layer (i.e., the 136 borehole). This heat flux is determined from building loads, which are generated using a building 137 energy simulation, along with the performance of the heat pump in the system.

139 This COMSOL heat conduction model uses approximately 11,000 three-dimensional triangular 140 prism domain elements, and 4,000 three-dimensional triangular prism boundary elements. The 141 element starting size at the internal surface of the grout is 0.06 meters, and an element growth rate 142 of 1.3 was used through the domain resulting in a maximum element size of 1.3 meters. The model 143 has a wall-clock runtime of approximately 5 to 7 hours per year of simulation time on a standard 
144 desktop personal computer. The other input parameters to the simulation are dependent on the soil

145 and grout properties, and the parameters used in this paper will be presented in Section 3.1.

146 The model developed by Law and Dworkin was originally used to study the effect of different

147 borehole layouts on ground thermal imbalance, and to determine long-term ground temperature

148 trends for different GSHP systems. The heat source in the model was taken as a known input to

149 the simulation process and was not calculated at each time-step based upon the interaction between

150 the GSHP system components with the ground. This study builds upon the work by Law and

151 Dworkin [22] by accounting for these interactions, including variable heat pump performance,

152 variable buildings loads, and also accounts for the interactions between a solar array with the 153 ground.

156 2. Analysis Technique

158 A time-stepping technique, combined with a thermal mass model, was used to analyze the solar-

159 assisted GSHP system. This section will provide an overview of the system being analyzed, along

160 with a detailed description of the analysis technique that was developed to perform the techno161 economic analysis.

162

\section{$163 \quad 2.1 \quad$ System Overview}

165 A schematic of the solar-assisted GSHP system is presented in Figure 2, which includes the major 166 system components, along with labels for important fluid states. 


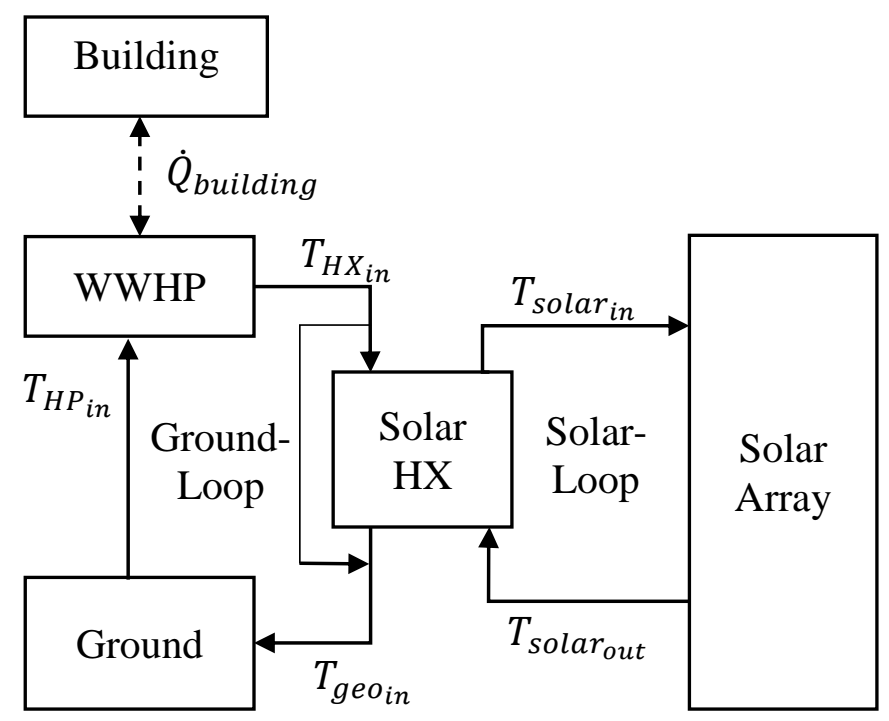

168

171 The building load component provides sensible heating and cooling loads as inputs to the water-

172 to-water heat pump (WWHP). The calculation of these loads is outside the scope of this paper, and

173 it is assumed that building loads are provided as inputs to this analysis process.

175 The ground component is modeled using the finite element technique, which allows for the 176 calculation of the temperatures within the ground. This model includes a single-borehole, along 177 with appropriate boundary conditions, to model a multi-borehole system. A detailed model is used 178 to calibrate a simplified model, such that computational times can be reduced. The details 179 associated with the detailed ground model are presented in Section 1.3, and the details associated 180 with the simplification technique and simplified model are presented in Section 2.2. 
182 The WWHP component can add/remove heat to/from the ground-fluid loop, and is used to meet

183 building loads. Manufacturer correlations for the WWHP are used to predict the performance of

184 this component. The details of the WWHP model are presented in Section 2.3.

185

186 The solar array component converts solar energy into heat, which is then added to the solar-fluid

187 loop in the form of sensible energy gain. The heat generated by the solar array is a function of the 188 operating parameters of the system, along with the solar array efficiency. The effects of pumps are 189 not considered in this study since they are negligible compared to the solar array energy transfers 190 and costs, as is consistent with the literature [24] [25]. The details of this model are presented in 191 Section 2.4.

192

193 The solar heat exchanger (Solar HX) is used to transfer heat from the solar-fluid loop to the ground194 fluid loop. This heat exchanger is required because potentially different fluids, and fluid flowrates, 195 may be used in these two fluid loops. The details of the model for this component are presented in 196 Section 2.5.

198 The overall system can operate in either heating or cooling mode. When the system is in heating 199 mode, the coefficient of performance (COP) of the WWHP is determined using the heating COP 200 correlation from manufacturer data. The WWHP will remove heat from the ground-loop fluid, 201 which reduces the ground-loop fluid temperature. Next, the ground-loop fluid enters the solar HX, 202 and if the outlet temperature of the solar-loop fluid from the solar array is greater than the ground203 loop fluid entering the solar HX, heat will be transferred from the solar-loop fluid to the ground204 loop fluid. Alternatively, the ground-loop fluid will bypass the solar HX and no heat is transferred. 
205 The ground-loop fluid then enters the ground, and depending on the temperature difference

206 between the ground-loop fluid and the ground there will be a resultant heat transfer, which is

207 calculated using the technique described in Section 2.6. The ground-loop fluid leaving the ground

208 then enters the WWHP, such that heat can be extracted at the next time-step.

209

210 Alternatively, when the system is in cooling mode, all components and control rules are the same,

211 except that heat will be added to the ground-loop fluid by the WWHP, and the COP of the heat

212 pump is found using the cooling COP correlation from manufacturer data. A more detailed

213 description of this analysis technique will be presented in Section 2.7.

\section{$215 \quad 2.2 \quad$ Simplified Ground Thermal Mass Model}

217 Detailed simulations of the solar-assisted GSHP system, which proved to be of high computational 218 cost, were carried out using the finite element model of the ground, as described in Section 1.3. 219 Therefore, a computationally efficient model that could approximate the performance of the 220 detailed model was desired.

222 To create this model, a simplification technique was developed, which used the detailed three223 dimensional finite element COMSOL model as a calibration tool for a simplified, 4-node

224 MATLAB thermal mass model. A difference in system performance estimation of up to 5\% was

225 deemed acceptable when comparing the detailed and simplified models. This acceptable error level 226 was also used during model development, and resulted in the selection of a 4-node model as 227 opposed to other node quantities. The schematic presented in Figure 3 shows the layout of the 228 nodes and the boundary conditions that were used in the simplified model. 


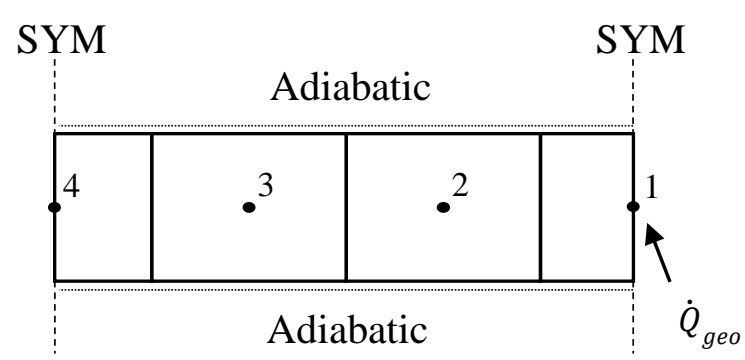

232 The heating/cooling load from the ground component in the overall system is applied to node 1,

233 which represents the location of the borehole. Nodes 2 and 3 are used to provide thermal mass and

234 spatial separation between nodes 1 and 4 . Lastly, node 4 represents the mid-point between two

235 boreholes in the multi-borehole system. This selection of boundary conditions allows this model

236 to represent interior boreholes of a linear geo-field. This representation was selected since it is a

237 conservative approach to modelling thermal imbalances in GSHP systems because a far-field and

238 constant temperature heat sink/source is not available to dissipate/restore these imbalances [22].

240 Each of the nodes in the simplified model requires a thermal mass determination, and each of the

241 node-to-node boundaries requires a product of the heat transfer coefficient and heat transfer area

242 determination. In what follows, the product of the heat transfer coefficient and heat transfer area

243 will be referred to as the heat transfer coefficient product. The thermal mass of a node relates the

244 temperature change of that node to the internal energy change of that node over a simulation time-

245 step. The heat transfer coefficient product between two adjacent nodes relates the temperature

246 gradient between these nodes to the heat transfer rate between these nodes over a simulation time-

247 step. The determination of these parameters was carried out using output data from the detailed 
248 finite element model, which will be referred to as the calibration in what follows. This calibration

249 was carried out by first determining the energy balance equation for each of the nodes in the model, 250 as shown in Figure 4 and Equation (1).

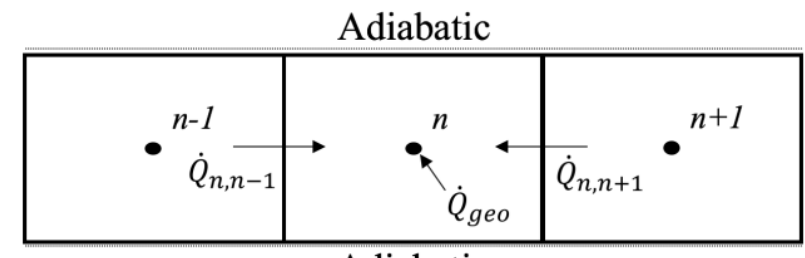

Adiabatic

$$
\sum \dot{Q}_{n}=\dot{Q}_{n, n-1}+\dot{Q}_{n, n+1}+\dot{Q}_{g e o}
$$

256 where $\sum \dot{Q}_{n}$ is the sum of all heat transfer rates into or out of any node $n$ in the simplified model,

$257 \dot{Q}_{n, n-1}$ is the heat transfer rate into node $n$ due to node $n-1, \dot{Q}_{n, n+1}$ is the heat transfer rate into 258 node $n$ due to node $n+1$, and $\dot{Q}_{g e o}$ is the heat transfer rate into node $n$ due to the borehole.

260 A general form of the energy balance was then derived for use with time-steps through the 261 simulation, and is shown in Equations (2) and (3).

262

$$
\begin{gathered}
\sum_{i=j}^{k-1} \dot{Q}_{i} \Delta t=\sum_{i=j}^{k-1}\left[\left(\dot{Q}_{n, n+1}\right)_{i}+\left(\dot{Q}_{n, n-1}\right)_{i}+\left(\dot{Q}_{g e o}\right)_{i}\right] \Delta t=\left(m c_{p}\right)_{n}\left(T_{n_{k}}-T_{n_{j}}\right) \\
\left(\dot{Q}_{n, x}\right)_{i}=(U A)_{n, x}\left(T_{x_{i}}-T_{n_{i}}\right)
\end{gathered}
$$


264 where $\left(m c_{p}\right)_{n}$ is the thermal mass of node $n, T_{n_{i}}$ is the instantaneous temperature of node $n$ at

265 time-step $i,\left(\dot{Q}_{n, x}\right)_{i}$ is the heat transfer rate between node $n$ and node $x$ (Note: $x=n+1$, or $x=$

$266 n-1)$ at time-step $i,(U A)_{n, x}$ is the product of the overall heat transfer coefficient $\left(U_{n, x}\right)$ and heat

267 exchange area $\left(A_{n, x}\right)$ of the ground between nodes $n$ and $x$, and $\Delta t$ is the length of a single time-

268 step. In what follows, it is important to note that there may be multiple time-steps between time-

269 steps $j$ and $k$.

270

271 For node 1 as node " $n$ ", since it is on a symmetric boundary, the heat transfer rate from node 2 as

272 node " $n+1$ " is also the heat transfer rate from the node " $n-1$ ". For nodes 2,3 , and 4 , the ground-

273 loop heat injection rate is equal to zero, since that load is only applied to node 1 . Lastly, for node

274 4, since it is also on a symmetric boundary, the heat transfer rate from node 3 is also the heat 275 transfer rate from the node " $n+1$ ".

277 Next, using the input ground loads and output temperature results from the detailed finite element 278 model, the thermal mass of node 1, and the heat transfer coefficient product between nodes 1 and 2792 can be determined. A linear system of equations can be set up as shown in Equation (4), which 280 is based upon Equation (2), and can be solved to yield the heat transfer coefficient product between $281 \quad$ nodes 1 and 2.

282

$$
\left[\begin{array}{cc}
T_{1_{k}}-T_{1_{j}} & -2 \Delta t \sum_{i=j}^{k-1}\left(T_{2_{i}}-T_{1_{i}}\right) \\
T_{1_{z}}-T_{1_{k}} & -2 \Delta t \sum_{i=k}^{z-1}\left(T_{2_{i}}-T_{1_{i}}\right)
\end{array}\right]\left(\begin{array}{l}
\left(m c_{p}\right)_{1} \\
(U A)_{1,2}
\end{array}\right)=\left[\begin{array}{c}
\Delta t \sum_{i=j}^{k-1} \dot{Q}_{g o_{i}} \\
\Delta t \sum_{i=k}^{z-1} \dot{Q}_{g e_{i}}
\end{array}\right]
$$


284 where $\mathrm{j}, k$, and $z$ represent equally spaced time-steps in the detailed model simulation, such as 285 time-step numbers $\mathrm{j}=1, \mathrm{k}=3$, and $\mathrm{z}=5$. In what follows, the spacing of these time-steps is defined 286 as the integration period.

288 At this point, the thermal mass of node 2 and the heat transfer coefficient product between nodes 2892 and 3 can be determined. A linear system of equations, as shown in Equation (5), can be solved 290 to determine these parameters.

291

$$
\left[\begin{array}{cc}
T_{2_{k}}-T_{2_{j}} & -\Delta t \sum_{i=j}^{k-1}\left(T_{3_{i}}-T_{2_{i}}\right) \\
T_{2_{z}}-T_{2_{k}} & -\Delta t \sum_{i=k}^{z-1}\left(T_{3_{i}}-T_{2_{i}}\right)
\end{array}\right]\left(\begin{array}{c}
\left(m c_{p}\right)_{2} \\
(U A)_{2,3}
\end{array}\right)=\left[\begin{array}{c}
(U A)_{1,2} \Delta t \sum_{i=j}^{k-1}\left(T_{1}-T_{2}\right)_{i} \\
(U A)_{1,2} \Delta t \sum_{i=k}^{z-1}\left(T_{1}-T_{2}\right)_{i}
\end{array}\right]
$$

293 The integration period used in this second system of equations will likely be larger than the spacing

294 used in the first system of equations. However, tuning of the integration period can be carried out 295 to determine values that result in acceptable simplified model predictions.

297 A similar process can be followed to determine the thermal mass of node 3 , and the heat transfer 298 coefficient product between nodes 2 and 3, using Equation (6).

299

$$
\left[\begin{array}{cc}
T_{3_{k}}-T_{3_{j}} & -\Delta t \sum_{i=j}^{k-1}\left(T_{4_{i}}-T_{3_{i}}\right) \\
T_{3_{z}}-T_{3_{k}} & -\Delta t \sum_{i=k}^{z-1}\left(T_{4_{i}}-T_{3_{i}}\right)
\end{array}\right]\left(\begin{array}{l}
\left(m c_{p}\right)_{3} \\
(U A)_{3,4}
\end{array}\right)=\left[\begin{array}{c}
(U A)_{2,3} \Delta t \sum_{i=j}^{k-1}\left(T_{2}-T_{3}\right)_{i} \\
(U A)_{2,3} \Delta t \sum_{i=k}^{z-1}\left(T_{2}-T_{3}\right)_{i}
\end{array}\right]
$$


301 Similarly, the integration period used in this third system of equations will likely be larger than

302 that used in the second system of equations.

303

304 Lastly, the thermal mass of node 4 can be determined using the relationship shown in Equation 305 (7).

$$
\left(m c_{p}\right)_{4}=\frac{2 \Delta t(U A)_{3,4}}{\left(T_{4 k}-T_{4 j}\right)} \sum_{i=j}^{k-1}\left(T_{2}-T_{3}\right)_{i}
$$

307 The integration period in Equation (7) will again likely be longer than that used in the third system 308 of equations.

310 Once the thermal mass of each node, and the heat transfer coefficient products between each of

311 the nodes are determined, the simplified nodal model can be used to approximate the results of the

312 detailed model. The temperature of each node in the simplified model at each time-step, as a

313 function of the ground heating load, can be determined using Equations (8) to (11). The initial 314 temperatures used in the simplified model should match the inputs used to the detailed model.

$$
\begin{gathered}
\left.T_{1_{i}}=T_{1_{i-1}}+\frac{\left[2(U A)_{1,2}\left(T_{2_{i-1}}-T_{1_{i-1}}\right)+\dot{Q}_{g e o}\right]}{\left(m c_{p}\right)_{1}}\right] \Delta t \\
T_{2_{i}=T_{2_{i-1}}+}+\frac{\left[(U A)_{1,2}\left(T_{1_{i-1}}-T_{2_{i-1}}\right)+(U A)_{2,3}\left(T_{3_{i-1}}-T_{2_{i-1}}\right)\right] \Delta t}{\left(m c_{p}\right)_{2}} \\
T_{3_{i}=T_{3 i-1}}+\frac{\left[(U A)_{2,3}\left(T_{2_{i-1}}-T_{3_{i-1}}\right)+(U A)_{3,4}\left(T_{4_{i-1}}-T_{3_{i-1}}\right)\right] \Delta t}{\left(m c_{p}\right)_{3}} \\
T_{4_{i}}=T_{4_{i-1}}+\frac{\left[2(U A)_{3,4}\left(T_{3_{i-1}}-T_{4_{i-1}}\right)\right] \Delta t}{\left(m c_{p}\right)_{4}}
\end{gathered}
$$


319 The COP of the WWHP was determined at each time-step in the simulation based upon 320 manufacturer data. A sample heating performance table is presented in Table 1, and a sample 321 cooling performance table is presented in Table 2.

Table 1: Sample heating COP data

\begin{tabular}{|c|c|c|c|c|c|c|}
\cline { 2 - 7 } \multicolumn{1}{c|}{} & \multicolumn{5}{c|}{ Leaving Load Hot Water Temperature $\left({ }^{\circ} \mathrm{C}\right)$} \\
\cline { 2 - 7 } \multicolumn{1}{c|}{} & \multicolumn{3}{c|}{40} & \multicolumn{3}{c|}{50} \\
\hline $\begin{array}{c}\text { Leaving Source } \\
\begin{array}{c}\text { Water } \\
\text { Temperature } \\
\left({ }^{\circ} \mathrm{C}\right)\end{array}\end{array}$ & $\begin{array}{c}\text { Power } \\
(\mathrm{kW})\end{array}$ & $\begin{array}{c}\text { Load } \\
(\mathrm{kW})\end{array}$ & $\begin{array}{c}\text { Heating } \\
\mathrm{COP}\end{array}$ & $\begin{array}{c}\text { Power } \\
(\mathrm{kW})\end{array}$ & $\begin{array}{c}\text { Load } \\
(\mathrm{kW})\end{array}$ & $\begin{array}{c}\text { Heating } \\
\mathrm{COP}\end{array}$ \\
\hline 5 & 10 & 30 & 3 & 11 & 27.5 & 2.5 \\
\hline 10 & 9 & 31.5 & 3.5 & 10 & 30 & 3 \\
\hline 15 & 8 & 32 & 4 & 9 & 31.5 & 3.5 \\
\hline
\end{tabular}

\begin{tabular}{|c|c|c|c|c|c|c|}
\cline { 2 - 7 } \multicolumn{1}{c|}{} & \multicolumn{5}{c|}{ Leaving Load Chilled Water Temperature $\left({ }^{\circ} \mathrm{C}\right)$} \\
\cline { 2 - 7 } \multicolumn{1}{c|}{} & \multicolumn{3}{c|}{5} & \multicolumn{3}{c|}{10} \\
\hline $\begin{array}{c}\text { Leaving Source } \\
\begin{array}{c}\text { Water } \\
\text { Temperature } \\
\left({ }^{\circ} \mathrm{C}\right)\end{array}\end{array}$ & $\begin{array}{c}\text { Power } \\
(\mathrm{kW})\end{array}$ & $\begin{array}{c}\text { Load } \\
(\mathrm{kW})\end{array}$ & $\begin{array}{c}\text { Cooling } \\
\text { COP }\end{array}$ & $\begin{array}{c}\text { Power } \\
(\mathrm{kW})\end{array}$ & $\begin{array}{c}\text { Load } \\
(\mathrm{kW})\end{array}$ & $\begin{array}{c}\text { Cooling } \\
\mathrm{COP}\end{array}$ \\
\hline 20 & 8 & 40 & 5 & 7 & 42 & 6 \\
\hline 25 & 9 & 36 & 4 & 8 & 40 & 5 \\
\hline 30 & 10 & 30 & 3 & 9 & 36 & 4 \\
\hline
\end{tabular}

327 The "power" value is the electrical power consumption of the compressor in the heat pump, the

328 "load" value is the heat transfer rate to/from the heating, ventilation, and air conditioning (HVAC) 329 system of the building when the heat pump is in heating/cooling mode respectively, and the "COP" 
330 value represents the heating or cooling COP of the heat pump, depending on the mode of operation.

331 Since discrete operating parameters are given in these tables, interpolation must be used, or a

332 function can be created, that relates each of the performance parameters to the leaving water (load

333 and source) temperatures.

335 The operation data in these tables can also be used to define the minimum COP operating limit of 336 the heat pump, which is a result of a large temperature-difference between the evaporator and the

337 condenser. For example, when the heat pump is in heating mode, the COP drops as the leaving 338 source-water temperature drops. The minimum leaving source-water temperature given in these 339 tables often coincides with the operational limit of the heat pump, which is a leaving source-water 340 temperature of $5^{\circ} \mathrm{C}$ based upon the sample data in Table 1 . To account for this limit, when the heat

341 pump is in heating mode and the leaving source-water temperature is outside of this operating

342 limit, the heat pump COP is set to 1.0. This assumption implies that an auxiliary electrical heater

343 is used to meet the building heating load when the system is outside of the heating operating limit.

345 Similarly, these operating principals also apply to the heat pump when it is in cooling mode, but 346 the limit is defined as a maximum leaving source-water temperature. Using the sample data 347 presented in Table 2 to determine this limit, a maximum leaving source-water temperature of $30^{\circ} \mathrm{C}$ 348 is found. However, when the system is in cooling mode and the source-water temperature is outside 349 this limit, the heat pump is set to be inoperable, and the ground-loop fluid temperature does not 350 change when passing through the heat pump in this case. 
352 Alternatively, the maximum COP operating limit can be defined as when the heat pump operates

353 with a very small temperature difference between the evaporator and condenser. As this

354 temperature difference decreases, the COP of the heat pump increases because the pressure

355 difference that the compressor must produce becomes small. However, to ensure that a 356 conservative maximum heat pump performance is predicted, extrapolation beyond the maximum

357 COP from the manufacturer table is not carried out, and the maximum COP from the performance 358 table is used as the upper COP limit.

360 Using the COP from the table, along with the building loads at each given time-step, the heat being

361 added or removed from the fluid in the ground-loop can be determined. When the system is in

362 heating mode, the relationship shown in Equation (12) can be used to determine the heat transfer 363 rate from the fluid in the ground-loop into the heat pump. Alternatively, when the system is in 364 cooling mode, the relationship shown in Equation (13) can be used to determine the heat transfer 365 rate from the heat pump into the fluid in the ground-loop.

366

$$
\begin{aligned}
& \dot{Q}_{H P}=\dot{Q}_{\text {building }}\left(1-\frac{1}{\mathrm{COP}_{H}}\right) \\
& \dot{Q}_{H P}=\dot{Q}_{\text {building }}\left(1+\frac{1}{\mathrm{COP}_{C}}\right)
\end{aligned}
$$

368 where $\dot{Q}_{H P}$ is the heat transfer rate in/out of the ground-loop fluid, $\dot{Q}_{\text {building }}$ is the building load 369 which is positive for cooling load and negative for heating load, $C O P_{H}$ is the heating $\mathrm{COP}$ of the 370 heat pump, and $\mathrm{COP}_{C}$ is the cooling COP of the heat pump. 
372 Based upon this ground-loop heat transfer rate, the temperature of the fluid in the ground-loop

373 exiting the WWHP can be determined using Equation (14).

374

375

$$
T_{H P_{o u t}}=T_{H X_{i n}}=T_{H P_{i n}}+\frac{\dot{Q}_{H P}}{\dot{m}_{g e o} c_{p_{g e o}}}
$$

376 where $T_{H P_{\text {out }}}$ is the temperature of the fluid in the ground-loop exiting the heat pump, $T_{H X_{\text {in }}}$ is the

377 temperature of the fluid in the ground-loop entering the solar heat exchanger, and $T_{H P}$ in is the 378 temperature of the fluid in the ground-loop entering the heat pump.

380 Lastly, the electrical power consumption of the heat pump can also be determined using the COP 381 of the heat pump, as shown in Equation (15).

$$
\dot{W}_{H P}=\frac{\left|\dot{Q}_{\text {building }}\right|}{C O P}
$$

383 where $\dot{W}_{H P}$ is the electrical power consumption of the heat pump.

\section{$385 \quad 2.4 \quad$ Solar Panel Model}

387 The solar panel model used in this paper is based upon the ISO standard, second-order polynomial 388 efficiency curve, which is typically provided by manufactures for commercially available panels 389 [26]. This efficiency curve allows the efficiency of the solar panel $\left(\eta_{\text {solar }}\right)$ to be calculated based 390 upon the inlet temperature of fluid to the panel $\left(T_{i n}\right)$, the ambient air temperature $\left(T_{a}\right)$, and the total 391 incident solar radiation $\left(I_{c}\right)$. This relationship is shown in Equations (16) and (17). 


$$
\begin{gathered}
\eta_{\text {solar }}=\eta_{0}-a_{1} T_{r}-a_{2} T_{r}^{2} I_{c} \\
T_{r}=\frac{T_{\text {in }}-T_{a}}{I_{c}}
\end{gathered}
$$

393 where $\eta_{0}, a_{1}$, and $a_{2}$ are the panel second-order efficiency parameters from the manufacturer.

395 The incident solar radiation on the panel is calculated using hourly solar weather data based on the 396 geographic location of the system, and the orientation of the solar panel. The relationship shown 397 in Equation (18) can be used to determine the total solar panel irradiation as a function of time [5].

$$
I_{c}=I_{b, n} \cos \left(i_{c}\right)+I_{d, h} \cos ^{2}\left(\frac{\beta}{2}\right)+\rho I_{h} \sin ^{2}\left(\frac{\beta}{2}\right)
$$

400 where $I_{b, n}$ is the beam-normal solar irradiation from the weather data, $I_{d, h}$ is the diffuse-horizontal 401 irradiation from the weather data, $\rho$ is the ground reflectivity, $I_{h}$ is the total horizontal irradiation 402 from the weather data, $i_{c}$ is the angle between the solar irradiation vector and the panel normal, 403 and $\beta$ is the tilt angle of the panel from horizontal.

\subsection{Solar Heat Exchanger Model}

406

407 The solar heat exchanger is modeled using the log-mean temperature difference method, and 408 assuming a constant heat transfer coefficient product. This technique can be applied because the 409 ground-loop is set to operate using an on-off control scheme, and the heat transfer area of the heat 410 exchanger will not change as the system operates. Assuming a counter-flow heat exchanger, the 
411 heat transfer rate through the solar heat exchanger can be found using the relationship shown in 412 Equation (19) [27].

413

$$
\dot{Q}_{H X}=(U A)_{H X} \frac{\left(T_{\text {solar }_{\text {out }}}-T_{\text {geo }_{\text {in }}}\right)-\left(T_{\text {solar }_{\text {in }}}-T_{H X_{\text {in }}}\right)}{\ln \left(\frac{T_{\text {solar }_{\text {out }}}-T_{\text {geo }_{\text {in }}}}{T_{\text {solar }_{\text {in }}}-T_{H X_{\text {in }}}}\right)}
$$

415 where $\dot{Q}_{H X}$ is the heat transfer rate of the solar heat exchanger, $(U A)_{H X}$ is the product of the overall 416 heat transfer coefficient $\left(U_{H X}\right)$ and heat exchange area $\left(A_{H X}\right)$ of the solar heat exchanger, $T_{\text {solar }}$ out

417 is the temperature of the solar loop fluid exiting the solar array, $T_{\text {solar }}$ in is the temperature of the 418 solar loop fluid entering the solar array, and $T_{g e o_{i n}}$ is the temperature of the ground-loop fluid 419 entering the ground.

421 The resulting heat transfer rate can then be used to determine the exit temperatures of both fluids 422 from the solar heat exchanger. Equation (20) can be used for the ground-loop fluid exit 423 temperature, and Equation (21) can be used for the for the solar-loop fluid exit temperature.

$$
\begin{gathered}
T_{g o_{i n}}=T_{H X_{i n}}+\frac{\dot{Q}_{H X}}{\dot{m}_{g e o} c_{p_{g e o}}} \\
T_{\text {solar }_{\text {in }}}=T_{\text {solar }_{\text {out }}}-\frac{\dot{Q}_{H X}}{\dot{m}_{\text {solar }} c_{p_{\text {solar }}}}
\end{gathered}
$$

426 where $\dot{m}_{g e o}$ is the mass flow rate of fluid in the ground-loop, $c_{p_{g e o}}$ is the specific heat capacity of 427 the fluid in the ground-loop, $\dot{m}_{\text {solar }}$ is the mass flow rate of fluid in the solar-loop, and $c_{p_{\text {solar }}}$ is 428 the specific heat capacity of the fluid in the solar-loop. 
432 The interaction between the ground and the ground-loop fluid is modelled using a constant surface

433 temperature heat exchanger model, which is based upon the log mean temperature difference 434 method [27]. The inner-wall of the borehole pipe in the ground, which is set equal to the node-1 435 temperature in the thermal mass model (see Section 2.2), is assumed to be isothermal, and constant 436 over a time-step [28]. Therefore, the outlet temperature of the ground-loop fluid from the ground 437 can be found by using the relationship shown in Equation (22).

$$
T_{\text {geo out }_{\text {ou }}}=T_{H P_{\text {in }}}=T_{\text {ground }}-\left(T_{\text {ground }}-T_{g_{\text {eo }} \text { in }}\right) \exp \left(-\frac{(U A)_{g e o}}{\dot{m}_{g e o} c_{p_{\text {geo }}}}\right)
$$

440 where $T_{\text {geo }_{\text {out }}}$ is the exit temperature of the ground-loop fluid from the ground, $T_{\text {geo }}$ in is the inlet 441 temperature of the ground-loop fluid to the ground, $T_{\text {ground }}$ is the effective temperature of the 442 ground where the borehole is located, which is equal to the node 1 temperature of the simplified 443 nodal model, and $(U A)_{g e o}$ is the product of the overall heat transfer coefficient $\left(U_{g e o}\right)$ and heat 444 exchange area $\left(A_{g e o}\right)$ of the ground heat exchanger.

\subsection{Overall System Model}

448 The overall system simulation begins by running the detailed finite element model with hourly 449 building HVAC loads. Using the results of the detailed finite element model, and the simplification 450 technique described in Section 2.2, the thermal masses and heat transfer coefficient products for 451 each of the nodes and node boundaries can be determined. 
452 Next, the parameters of the system that are constant throughout the simulation, and do not need to

453 be re-calculated at each time-step, must be set. These parameters are shown in Table 3. A fixed

454 solar array orientation was used since active tracking was not considered for this study.

Table 3: Constant Parameters for Overall-System Simulation

\begin{tabular}{|l|c|}
\hline \multicolumn{1}{|c|}{ Parameter } & Symbol(s) \\
\hline Simulation time-step length & $\Delta t$ \\
\hline $\begin{array}{l}\text { Weather data input file with air temperature, horizontal, } \\
\text { diffuse-horizontal, and beam irradiation values }\end{array}$ & $T_{a}, I_{h}, I_{d, h}, \& I_{b, n}$ \\
\hline Building load file & $\dot{Q}_{\text {building }}$ \\
\hline Location information (longitude and latitude) & $L_{\text {building, }} l_{\text {building }}$ \\
\hline Solar array area & $A_{\text {solar }}$ \\
\hline Solar array tilt angle & $\beta$ \\
\hline Solar array azimuth angle & $a_{w}$ \\
\hline Solar array performance correlation & $\eta_{\text {solar }}=F\left(T_{r}, \dot{q}_{\text {solar }}\right)$ \\
\hline Heat pump heating performance correlation & $C O P_{H}=F\left(T_{H P_{\text {out }}}\right)$ \\
\hline Heat pump cooling performance correlation & $C O P_{C}=F\left(T_{H P}\right)$ \\
\hline Ground-loop fluid mass flowrate when operating & $\dot{m}_{\text {geo }}$ \\
\hline Solar-loop fluid mass flowrate when operating & $\dot{m}_{\text {solar }}$ \\
\hline Specific heat capacity of fluid in ground-loop & $c_{p_{\text {geo }}}$ \\
\hline Specific heat capacity of fluid in solar-loop & $c_{p_{\text {solar }}}$ \\
\hline Heat transfer coefficient product of ground heat exchanger & $(U A)_{\text {geo }}$ \\
\hline $\begin{array}{l}\text { Heat transfer coefficient product of the solar heat } \\
\text { exchanger }\end{array}$ & $(U A)_{H X}$ \\
\hline $\begin{array}{l}\text { Nodal ground heat capacities and heat transfer coefficient } \\
\text { products }\end{array}$ & $\left(m c_{p}\right)_{n^{\prime}}(U A)_{n, x}$ \\
\hline Ground initial temperature & $T_{\text {ground }}$ \\
\hline
\end{tabular}

458 After setting the constant system parameters, all fluid temperatures in the system must be 459 initialized to the initial ground temperature. The effect of different initial fluid temperatures was 460 investigated using a one-year simulation, and these changes were found to have negligible effects 461 on the annual system performance. 
463 Next, the heat pump COP at the current time-step can be determined using the outlet temperature

464 from the heat pump, or the outlet temperature from the previous time-step if it is not the first time-

465 step, using the process described in Section 2.3. If the outlet temperature from the heat pump is

466 found to be outside the heat pump operating limits, then the COP of the heat pump is set to 1.0

467 when in heating mode, or is considered inoperable when in cooling mode. Conversely, if the COP

468 of the heat pump is found to be above the maximum COP operating limit, then the COP is set to

469 the maximum rated COP of the heat pump. Using this COP, the heat transfer between the ground-

470 loop fluid and the heat pump can be determined using Equation (12) if the system is in heating

471 mode, or Equation (13) if the system is cooling mode.

472

473 Using this ground-loop heat transfer rate, the exit temperature of the fluid from the heat pump can

474 be determined using Equation (14). This temperature is also equal to the temperature of the ground-

475 loop fluid that enters the solar heat exchanger. The heat pump COP can then be used to determine

476 the power consumption of the heat pump using Equation (15).

478 At this point, the performance of the solar array must be determined as a function of the current 479 time-step fluid temperatures and weather conditions, using the process detailed in Section 2.4. This 480 determination will yield the current time-step exit temperature of solar-loop fluid from the solar 481 array, and the useful heat collected by the solar array. If a negative heat collection is found at the 482 current time-step, the mass flowrate of the fluid in the solar-loop and the solar heat collection by 483 the solar array are set to zero. 
485 The heat transfer rate of the solar heat exchanger, along with the fluid exit temperatures from the 486 solar heat exchanger, can be determined at this point using the process described in Section 2.5. 487 The temperature of the fluid in the solar-loop exiting the solar array, which is equal to the 488 temperature of the solar-loop fluid entering the solar heat exchanger, must be compared to the 489 temperature of the fluid in the ground-loop entering the solar heat exchanger. If this solar-loop 490 fluid temperature is greater than this ground-loop fluid temperature, and both fluid loops have a 491 non-zero flowrate, then the solar heat exchanger will operate. Otherwise, the heat transfer rate 492 through the solar heat exchanger is set to zero, the outlet temperatures of both fluid streams are set 493 equal to the respective inlet temperatures of each stream, and the ground-loop fluid bypasses the 494 solar heat exchanger.

495

496 Lastly, the heat transfer rate between the ground-loop fluid and the ground is found using the 497 process described in Section 2.6. Based upon the resulting heat transfer rate between the ground498 loop fluid and the ground, the outlet temperature of the ground-loop fluid can be determined. This 499 heat transfer rate is then used to determine nodal temperatures using Equations (8) through (11). 500 The flow chart presented in Figure 5 illustrates the overall simulation process. 
1) Run the detailed finite element model, and determine the simplified model thermal masses and heat transfer coefficient products.

2) Set the constant model parameters.

3) Initialize all fluid temperatures.

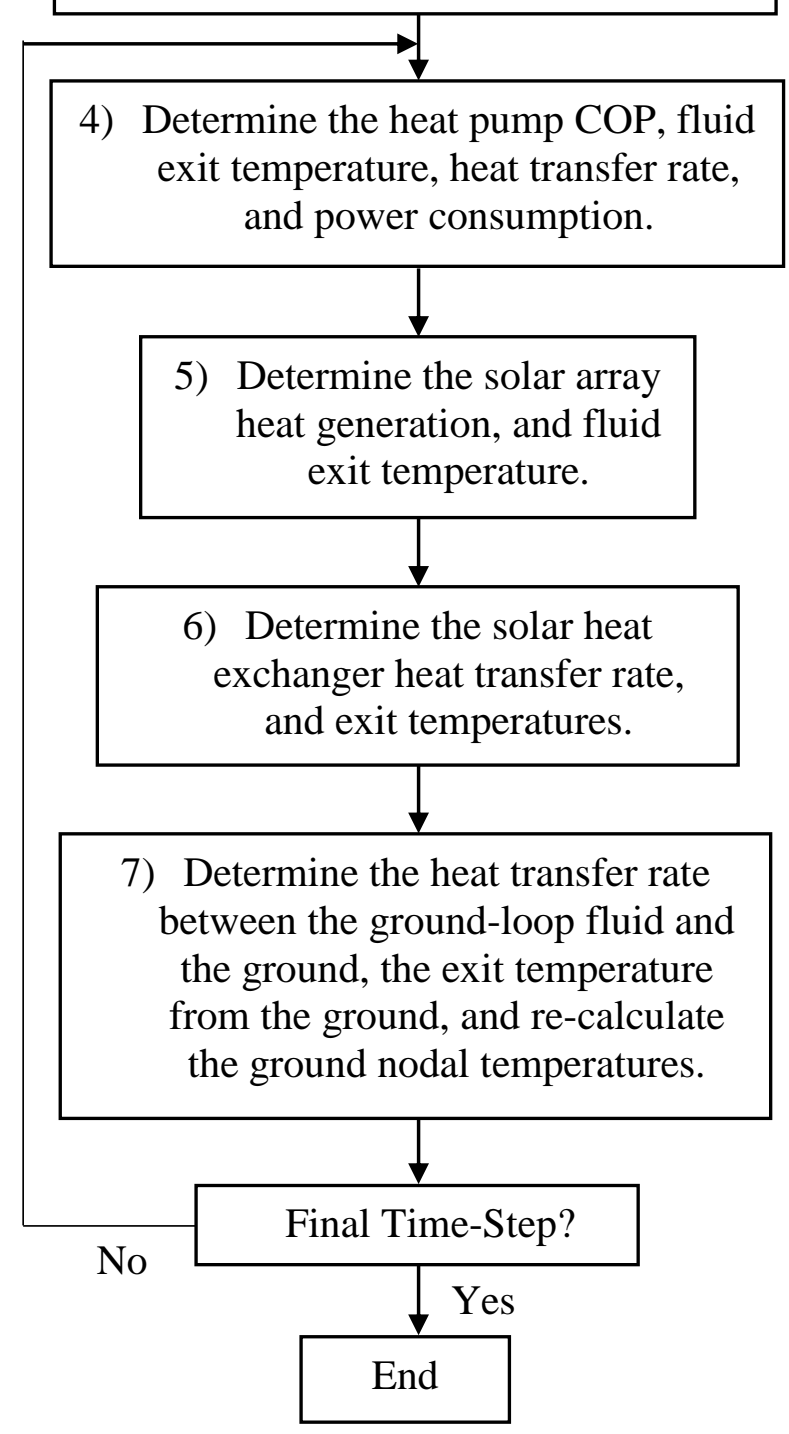

Figure 5: Overall system model flowchart 
505 Steps 4 through 7, as shown in Figure 5, are repeated for each time-step in the simulation. After

506 the solution process has been carried out for the final time-step of the simulation, the analysis of

507 the system is complete. Case studies that illustrate the application of this analysis technique will

508 be presented in Section 3.

509

510

$511 \quad 3 . \quad$ Model Case Study Results

512

513 This section presents case studies that were carried out using the analysis technique discussed in

514 Section 2. The details related to the energy modelling of the system are presented in Section 3.1,

515 and the economic analysis that was carried out based upon the results of the energy study are

516 presented in Section 3.2.

\subsection{Energy and Technical Feasibility Study}

520 The technique described in Section 2 was used to analyze a solar-assisted GSHP system for use

521 with three different buildings in Toronto, Canada. The building loads from these buildings were

522 provided as inputs to the analysis, and were generated by a building energy simulation software

523 which is outside the scope of this study. The first building was an event space, and had an annual

524 heating-to-cooling load ratio of 20.4:1. The second building was an office, and had an annual

525 heating-to-cooling load ratio of 8.6:1. The third building was a school, and had an annual heating-

526 to-cooling load ratio of 1.2:1. These buildings were selected because of the range in building

527 heating-to-cooling ratios that they provided. Figure 6 shows the building loads for each of the 
528 different buildings. In what follows, the start date of the simulations was taken as November 1, to 529 represent the system being commissioned over the summer and fall, in preparation for winter.
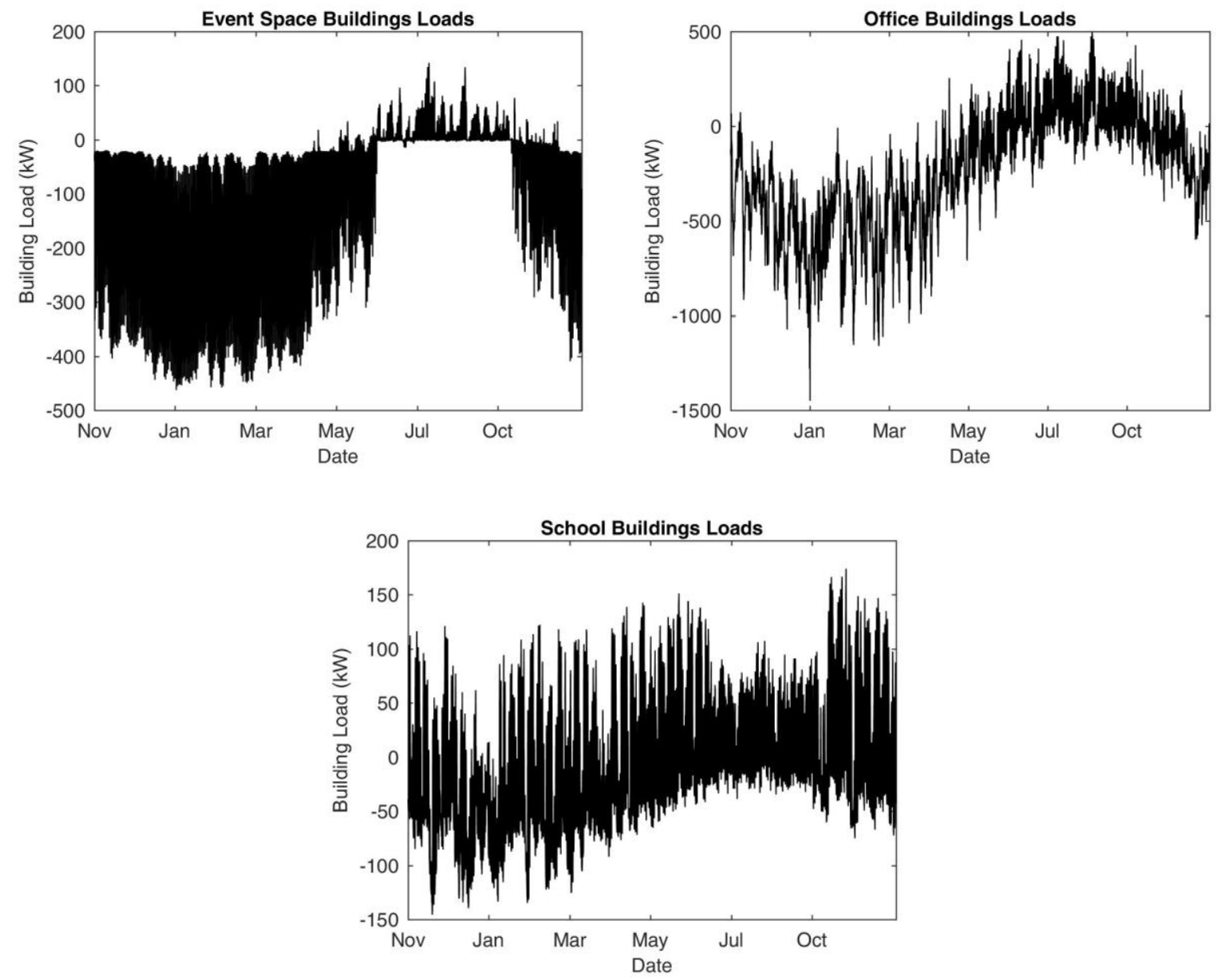

Figure 6: Case study building loads

534 The heat pump efficiency characteristics that were used in this study were based upon the

535 Multistack 070NX, and the performance tables for this heat pump can be found in the product 536 manual [29]. This heat pump model was selected based upon the building load requirements of the 537 event venue, and normalized performance was used for each of the studies. Based upon 538 consultation with industry, the temperature of the hot water leaving the heat pump and being sent 539 to the building HVAC system was set to be constant at $49^{\circ} \mathrm{C}$ while in heating mode. Similarly, 
540 while in cooling mode, the temperature of the chilled water leaving the heat pump and being sent

541 to the building $\mathrm{HVAC}$ system was set constant at $8.9^{\circ} \mathrm{C}$.

543 The analysis process began by first creating calibration ground-load files for use with the detailed

544 finite element model, such that calibration temperatures for the simplified model could be

545 generated. In these simulations, a constant heating COP of 4 was used when the system was in

546 heating mode, a constant cooling COP of 3 when in cooling mode, and no solar panels were

547 included. Table 4 summarizes the other input parameters to these simulations.

Table 4: Simulation input parameters for obtaining ground loads

\begin{tabular}{|c|c|c|}
\hline Parameter & Value(s) & Symbols(s) \\
\hline Weather data input file & Toronto CWEC Data [30] & $\rho, T_{a}, I_{h}, I_{d, h}, \& I_{b, n}$ \\
\hline Building load file & See Figure 6 & $\dot{Q}_{\text {building }}$ \\
\hline $\begin{array}{l}\text { Location information (longitude and } \\
\text { latitude) }\end{array}$ & $43.67 N, 79.38 W$ & $L_{\text {building }}, l_{\text {building }}$ \\
\hline \multirow{2}{*}{$\begin{array}{l}\text { Ground-loop fluid mass flowrate } \\
\text { when operating }\end{array}$} & $025 \mathrm{~kg} / \mathrm{s}$ & $\dot{m}_{g e o}$ \\
\hline & $0.25 \overline{\text { ton }_{\text {peak }}}$ & $\dot{Q}_{\text {building }}{ }_{\text {peak }}$ \\
\hline $\begin{array}{l}\text { Specific heat capacity of fluid in } \\
\text { ground-loop }\end{array}$ & $\begin{array}{c}3449 \mathrm{~J} / \mathrm{kgK} \\
(50 / 50 \text { propylene glycol-water mix })\end{array}$ & $c_{p_{g e o}}$ \\
\hline $\begin{array}{l}\text { Specific heat capacity of fluid in } \\
\text { solar-loop }\end{array}$ & $\begin{array}{c}3449 \mathrm{~J} / \mathrm{kgK} \\
(50 / 50 \text { propylene glycol-water mix })\end{array}$ & $c_{p_{\text {solar }}}$ \\
\hline Ground initial temperature & $10^{\circ} \mathrm{C}[22]$ & $T_{\text {ground }}$ init \\
\hline Soil conductivity & $2 W / m K[22]$ & $k_{\text {soil }}$ \\
\hline Soil specific heat capacity & $1053 \mathrm{~J} / \mathrm{kgK}[22]$ & $c_{p_{\text {soil }}}$ \\
\hline Soil density & $1900 \mathrm{~kg} / \mathrm{m}^{2}[22]$ & $\rho_{\text {soil }}$ \\
\hline Grout conductivity & $0.7 \mathrm{~W} / \mathrm{mK}[22]$ & $k_{\text {grout }}$ \\
\hline Grout specific heat capacity & $1647 \mathrm{~J} / \mathrm{kgK}[22]$ & $c_{p_{\text {grout }}}$ \\
\hline Grout density & $1700 \mathrm{~kg} / \mathrm{m}^{2}[22]$ & $\rho_{\text {grout }}$ \\
\hline Solar panel area & $2.65 \mathrm{~m}^{2} /$ panel & $A_{\text {solar }} / N_{\text {panel }}$ \\
\hline Solar panel intercept efficiency & 0.852 & $\eta_{0}$ \\
\hline Solar panel efficiency slope & $3.92 \mathrm{~W} / \mathrm{m}^{2} \mathrm{~K}$ & $a_{1}$ \\
\hline Solar panel efficiency curvature & $0.015 \mathrm{~W} / \mathrm{m}^{2} \mathrm{~K}^{2}$ & $a_{2}$ \\
\hline Solar mass flow rate when operating & $0.00945 \mathrm{~kg} / \mathrm{m}^{2} \mathrm{~s}$ & $\dot{m}_{\text {solar }} / A_{\text {solar }}$ \\
\hline
\end{tabular}


551 These simulations were run using 1-hour time-steps, and the resulting ground loads are shown in $552 \quad$ Figure 7.

553

554
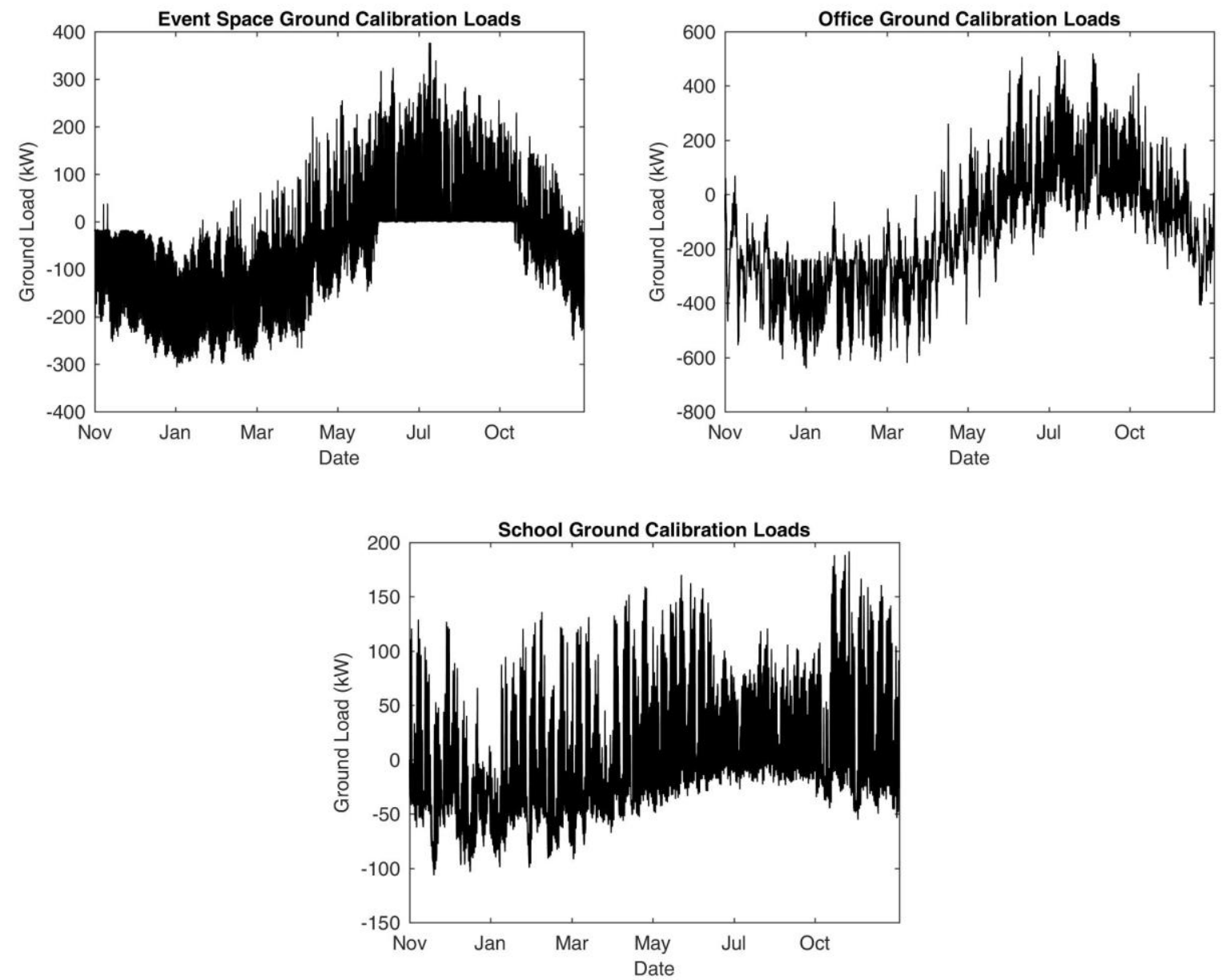

Figure 7: Calibration ground loads for nodal model

558 These loads were used as the input values to the detailed finite element model, and to illustrate

559 typical results, the temperatures of the four nodes for the event space are presented in Figure 8.

560 Node 1 contains the ground heat load and is coincident with the location of the borehole. Node 2

561 is one meter away from the borehole, node 3 is two meters away from the borehole, and node 4 is

562 at the symmetric boundary conditions, which is three meters away from the borehole. 

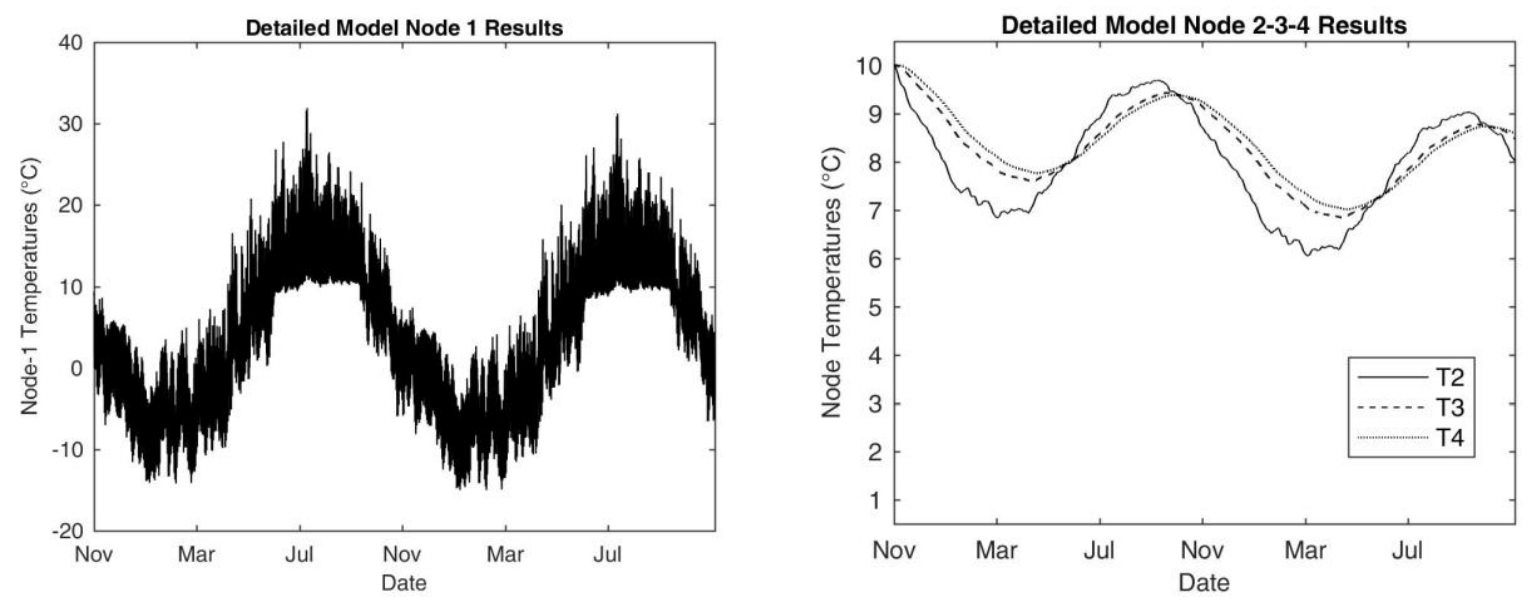

Figure 8: Detailed finite element model node temperatures for the event-venue case

565 The temperature arrays for all nodes from the detailed finite element model were then used to

566 calibrate the thermal mass model for each building. The integration periods for all of the nodal

567 matrix calculations, the resulting specific heat capacities based on the simplification technique as

568 shown in Equation (2), and the resulting heat transfer coefficient products as shown in Equation

569 (3) are presented in Table 5.

570

571

Table 5: Simplified nodal heat capacities and heat transfer coefficient products

\begin{tabular}{|c|c|c|c|c|}
\hline Value & $\begin{array}{c}\text { Node or } \\
\text { Interface }\end{array}$ & Event Space & Office & School \\
\hline \multirow{3}{*}{$\begin{array}{c}\text { Integration } \\
\text { Periods (hours) }\end{array}$} & 1 & 20 & 5 & 18 \\
\cline { 2 - 5 } & 2 & 150 & 200 & 150 \\
\cline { 2 - 5 } & 3 & 1,000 & 1,000 & 1,000 \\
\hline \multirow{3}{*}{$\begin{array}{c}\text { Specific Heat } \\
\text { Capacity }\left(\frac{J}{K}\right)\end{array}$} & 1 & $1.38 \times 10^{8}$ & $3.82 \times 10^{8}$ & $4.56 \times 10^{7}$ \\
\cline { 2 - 5 } & 2 & $7.33 \times 10^{10}$ & $2.41 \times 10^{11}$ & $3.56 \times 10^{10}$ \\
\cline { 2 - 5 } & 4 & $4.60 \times 10^{10}$ & $4.13 \times 10^{11}$ & $2.55 \times 10^{10}$ \\
\hline Heat Transfer & $1-2$ & $6.40 \times 10^{12}$ & $7.47 \times 10^{12}$ & $1.45 \times 10^{11}$ \\
\cline { 2 - 5 } Coefficient & $2-3$ & $5.29 \times 10^{4}$ & $4.36 \times 10^{4}$ & $3.18 \times 10^{3}$ \\
\cline { 2 - 5 } Product $\left(\frac{W}{K}\right)$ & $3-4$ & $1.47 \times 10^{5}$ & $1.17 \times 10^{6}$ & $2.39 \times 10^{4}$ \\
\hline \multirow{2}{*}{} & & & & $5.98 \times 10^{4}$ \\
\hline
\end{tabular}


573 The simplified model was then run using the same calibration ground loads that were used in the

574 detailed model, along with the nodal heat capacities and heat transfer coefficient products as shown

575 in Table 5. Plots of the node 1 and node 4 temperatures for each of the buildings and time-steps in

576 the calibration simulation from the detailed and simplified models are shown in Figure 9.
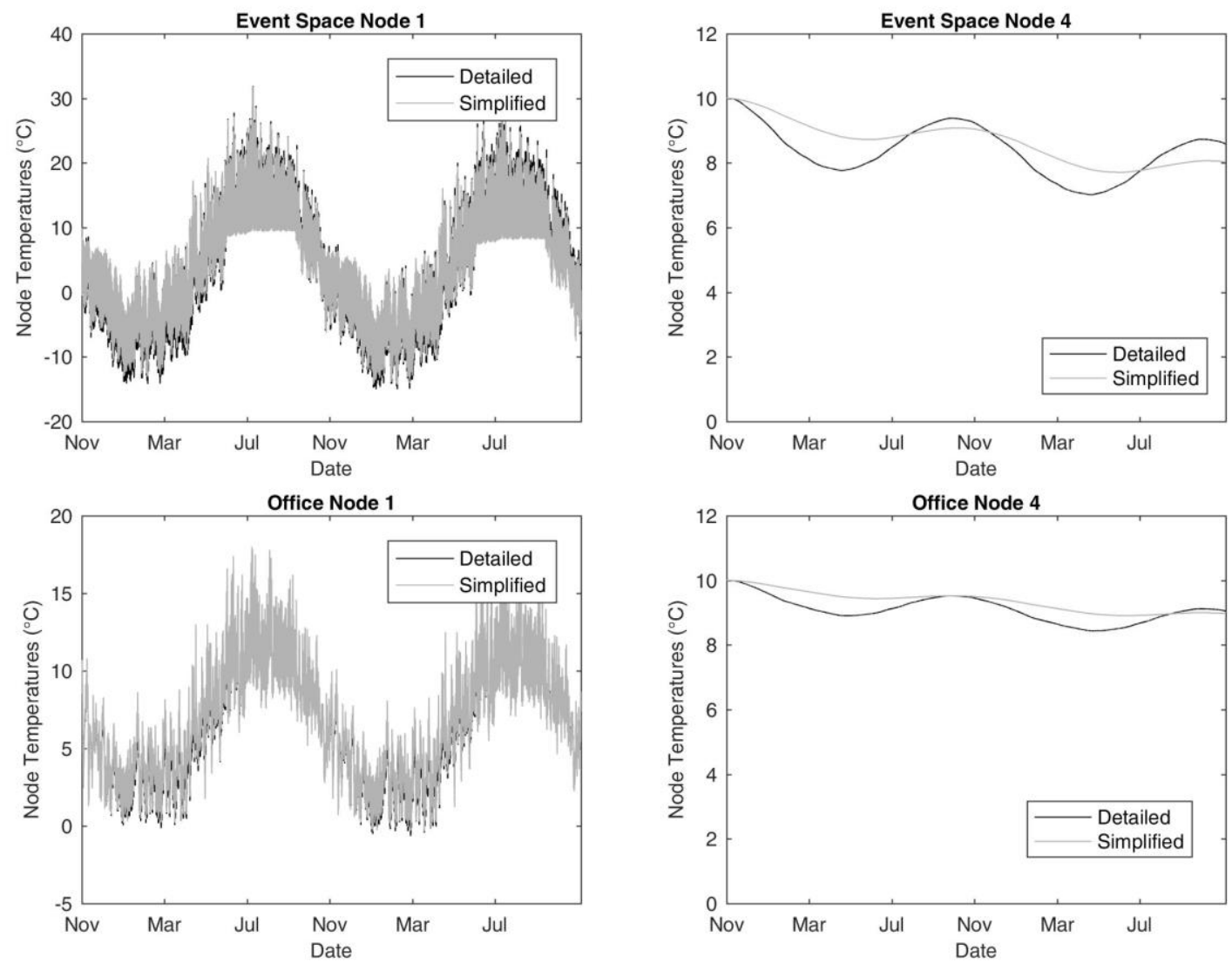

578
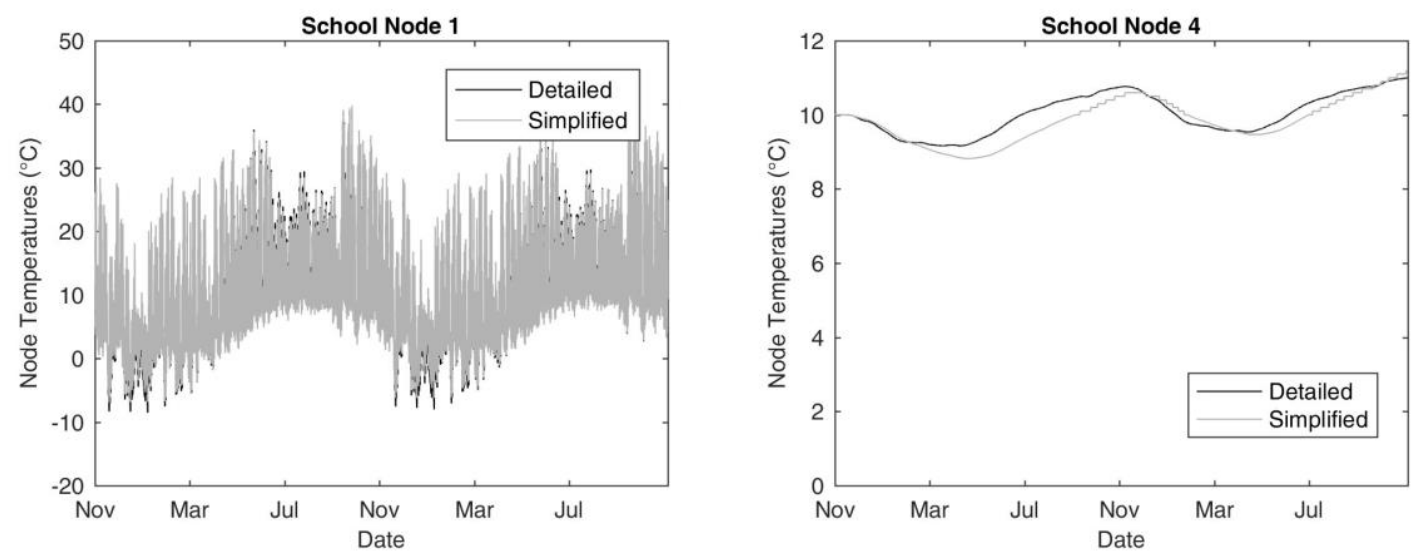

580

Figure 9: Comparative node 1 and node 4 temperatures from the calibration simulations 
582 The node 1 temperature arrays from the detailed and simplified models were then used to compute

583 the electrical energy consumption of the heat pump over the calibration period. The calculation

584 process described in Section 2.3 was used. The resulting electrical energy consumption of the

585 compressor for each of the models was then summed over the calibration period, and the difference

586 between these two sums was used to check the accuracy of the calibration process. This check was

587 carried out to validate that the simplified model can predict the same overall system performance

588 as the detailed model, which has been definitively established, noting that the detailed model has

589 been thoroughly validated in literature [22]. Since the end use of the simplified model is to compare

590 the effect that different quantities of solar panels have on overall system performance, this

591 validation is deemed to be sufficient. Other values of interest for the calibration process were the

592 detailed model temperature range, simplified model temperature range, maximum absolute

593 temperature difference between the two models, and the average absolute temperature difference

594 between the two models. A summary of these results for each of the buildings is shown in Table

5956.

Table 6: Summary of detailed and simplified model comparison results

\begin{tabular}{|c|c|c|c|c|}
\hline $\begin{array}{l}\text { Node } \\
\text { Number }\end{array}$ & Value & Event Space & Office & School \\
\hline N/A & $\begin{array}{c}\text { Absolute Compressor } \\
\text { Energy Consumption } \\
\text { Difference }\end{array}$ & $4.7 \%$ & $4.8 \%$ & $3.9 \%$ \\
\hline \multirow{4}{*}{1} & Detailed Model Range & $-14.2^{\circ} \mathrm{C}-31.9^{\circ} \mathrm{C}$ & $-0.15^{\circ} \mathrm{C}-16.67^{\circ} \mathrm{C}$ & $-8.53^{\circ} \mathrm{C}-39.49^{\circ} \mathrm{C}$ \\
\hline & $\begin{array}{c}\text { Simplified Model } \\
\text { Range }\end{array}$ & $-13.1^{\circ} \mathrm{C}-31.9^{\circ} \mathrm{C}$ & $0.19^{\circ} \mathrm{C}-17.98^{\circ} \mathrm{C}$ & $-6.94^{\circ} \mathrm{C}-39.83^{\circ} \mathrm{C}$ \\
\hline & $\begin{array}{c}\text { Maximum Absolute } \\
\text { Difference }\end{array}$ & $8.07^{\circ} \mathrm{C}$ & $3.24^{\circ} \mathrm{C}$ & $9.51^{\circ} \mathrm{C}$ \\
\hline & $\begin{array}{c}\text { Average Absolute } \\
\text { Difference }\end{array}$ & $1.96^{\circ} \mathrm{C}$ & $0.63^{\circ} \mathrm{C}$ & $1.61^{\circ} \mathrm{C}$ \\
\hline \multirow{4}{*}{4} & Detailed Model Range & $7.77^{\circ} \mathrm{C}-10.0^{\circ} \mathrm{C}$ & $8.91^{\circ} \mathrm{C}-10.00^{\circ} \mathrm{C}$ & $9.16^{\circ} \mathrm{C}-10.0^{\circ} \mathrm{C}$ \\
\hline & $\begin{array}{c}\text { Simplified Model } \\
\text { Range }\end{array}$ & $8.49^{\circ} \mathrm{C}-10.0^{\circ} \mathrm{C}$ & $9.43^{\circ} \mathrm{C}-10.00^{\circ} \mathrm{C}$ & $8.82^{\circ} \mathrm{C}-10.0^{\circ} \mathrm{C}$ \\
\hline & $\begin{array}{c}\text { Maximum Absolute } \\
\text { Difference }\end{array}$ & $0.96^{\circ} \mathrm{C}$ & $0.8^{\circ} \mathrm{C}$ & $0.66^{\circ} \mathrm{C}$ \\
\hline & $\begin{array}{c}\text { Average Absolute } \\
\text { Difference }\end{array}$ & $0.51^{\circ} \mathrm{C}$ & $0.28^{\circ} \mathrm{C}$ & $0.23^{\circ} \mathrm{C}$ \\
\hline
\end{tabular}


597 The full-system model was then run using the thermal mass parameters shown in Table 5, along 598 with the additional system parameters shown in Table 7.

599

600

Table 7: Summary of building specific system parameters

601

\begin{tabular}{|c|c|c|c|}
\hline & Event space & Office & School \\
\hline $\begin{array}{c}\text { Calculated heat transfer } \\
\text { product of ground heat } \\
\text { exchanger }(\mathrm{W} / \mathrm{K})\end{array}$ & $6.86 \times 10^{4}$ & $2.15 \times 10^{5}$ & $2.58 \times 10^{4}$ \\
\hline $\begin{array}{c}\text { Calculated ground-loop } \\
\text { fluid mass flowrate } \\
\text { when operating }(\mathrm{kg} / \mathrm{s})\end{array}$ & 24.9 & 78.0 & 9.36 \\
\hline
\end{tabular}

602 Each run considered a new quantity of solar panels, and each simulation was run using a 40-year

603 simulation period. The ground temperatures determined using the simplified nodal model were

604 used to determine the performance of the heat pump and solar array at each time-step in the

605 simulation period, which allowed for the interaction between all system components to be

606 represented. The plots shown in Figure 10 illustrates the effect of additional solar panels on the

607 long-term temperature response of node 4 from the event space, office, and school.

608 

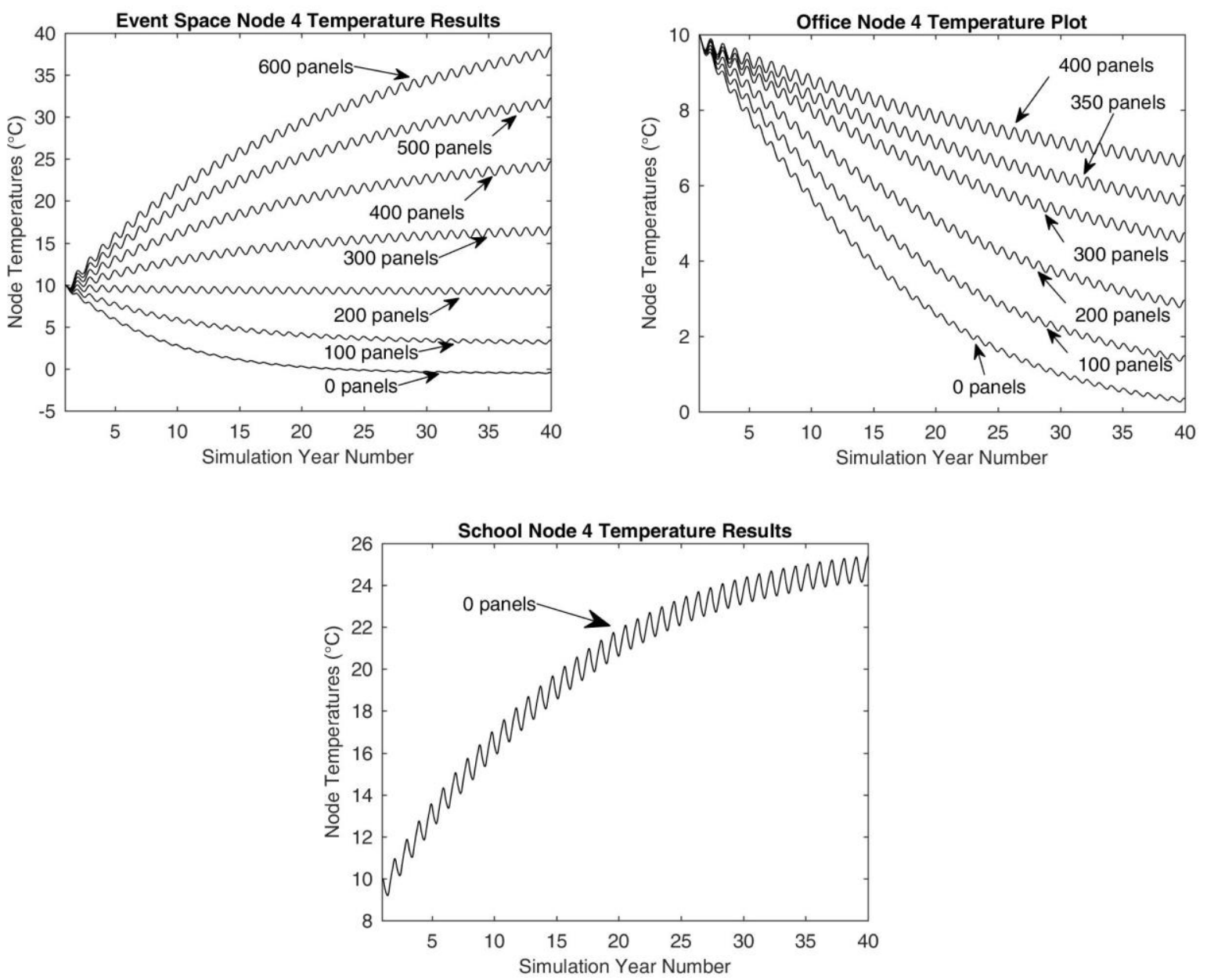

Figure 10: Node 4 temperature results for different numbers of solar panels.

613 The results, as shown in Figure 10, show both short-term fluctuations and long-term changes in

614 ground temperature. The short-term fluctuations are caused by the seasonal variations in ground

615 loads, which cause a decrease in ground temperature during the winter months, and an increase in

616 ground temperature during the summer months. If the annual ground loads are balanced, these

617 short-term fluctuations are approximately equal to each other, as shown by the 200-panel curve

618 for the event space in Figure 10. However, if the annual ground loads are imbalanced, then one of

619 the seasonal fluctuations will be consistently larger than the opposing seasonal fluctuation, which 
620 will lead to a long-term temperature change. The 0-panel curve for the office in Figure 10

621 represents a case with winter ground temperature decreases that are consistently more than the

622 summer temperature increases, which leads to a long-term decrease in ground temperature. This

623 temperature decrease reduces the amount of heat that can be removed from the ground, which

624 causes the heat pump COP to decrease, and leads to the asymptotic trend in long-term ground

625 temperature. Conversely, as shown by the 0-panel curve for the school in Figure 10, the summer

626 ground temperature increases are larger than the winter temperature decreases, which leads to

627 long-term ground temperature increases.

628

629 The minimum number of panels that a system could use, while still being considered viable, is

630 based on ground thermal imbalance as discussed in Section 1.2. In this study, the ground was

631 considered thermally imbalanced when the operation of the heat pump was outside its minimum

632 COP operating limit for more than $10 \%$ of the time-steps in a given simulation year. In what

633 follows, the fraction of time-steps that the heat pump COP is below the minimum COP operating

634 limit, for either heating or cooling, to the total number of time-steps is defined as the imbalance

635 factor. Plots of the annual heating imbalance factors for each number of solar panels for the event 636 space, office, and school are presented in Figure 11.

637 

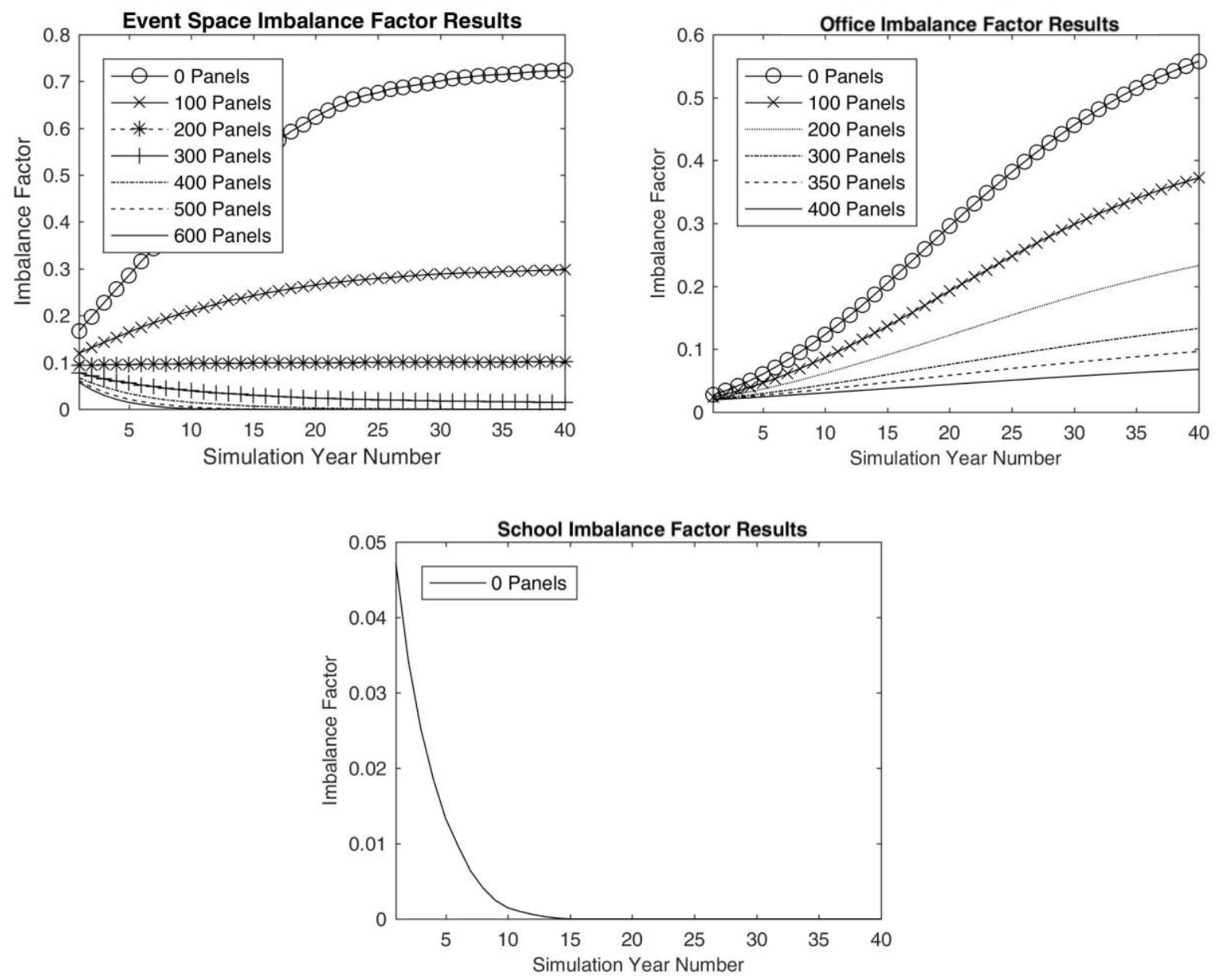

641 The results for the event space, as shown in Figure 11, show that if approximately 200 panels or

642 more are used, the system will be viable for at least 40 years based on a maximum acceptable

643 imbalance factor of $10 \%$. However, if more than 200 panels are used, the system will experience

644 a decrease in cooling efficiency over the 40-year lifetime, since the ground will get warmer from

645 excessive heat addition, and will have a higher initial cost since more solar panels must be

646 purchased.

647 As shown in Figure 11 for the office, to ensure an imbalance factor of $10 \%$ is not exceed after 40

648 years of operation, approximately 350 solar panels are needed. It is important to note that although

649 the annual HVAC heating-to-cooling energy demand of the office is $8.6: 1$, compared to a ratio of 
650 20.4:1 for the event space, that the total annual heating energy demand of the office is 651 approximately 2.4 times larger than that of the event space. This combination of imbalanced

652 HVAC loads and the total energy demand of the building is the overall contributor to the ground 653 thermal response and number of solar panels that are needed.

655 For the school, with an annual heating-to-cooling load ratio of 1.2:1, no solar panels are needed to 656 ensure the school does not exceed an imbalance factor of $10 \%$. This result occurs since the HVAC 657 energy demands of the school result in net positive heat transfer to the ground, and the long-term 658 temperature change of the ground does not negatively impact the system COP over a 40-year 659 lifetime. Therefore, a solar-assisted GSHP system does not need to be recommended for buildings 660 with a 1.2:1 heating-to-cooling load ratio.

662 A comparison between the results of this study to the results of a similar study by Emmi et al. [14] 663 has also been carried out to determine the reliability of this model when estimating overall system 664 performance. The study by Emmi et al. investigated using a solar-assisted GSHP system to reduce 665 the total borehole length required for a system. Their results presented a relationship between the 666 solar array size and the minimum temperature of the fluid entering the ground heat exchanger each 667 year in the simulation. The results of this comparison showed that there are matching trends in 668 fluid temperatures entering the borehole field when adding solar panels, and that there is an ability 669 to alleviate ground thermal imbalance by adding solar panels. However, in contrast to the present 670 study, the study by Emmi et al. only investigated a single solar array size for each building, and 671 did not investigate the impact of different array sizes for individual buildings. 
673 Using these results, a financial study was carried out for the event space and office, since only

674 these two buildings require solar panels to avoid ground thermal imbalance. The economic impact

675 of purchasing panels beyond the minimum number required to avoid ground thermal imbalance

676 was investigated, and the details of this analysis will be discussed in Section 3.2.

677

\section{$678 \quad 3.2 \quad$ Economic Analysis}

680 The economic analysis of the solar-assisted GSHP system was carried out using a net-present cost

681 (NPC) analysis method. The NPC method converts all costs to present day values, which allows

682 for an equal comparison between systems that have variable operating costs over the lifetimes of

683 the systems. The system parameters that result in the lowest net-present cost is typically the most

684 preferable if the system is fit for purpose over its lifetime, and if the upfront cost of that system is

685 within the budget of the specific project. The relationship shown in Equation (23) can be used to 686 determine the NPC of an installation [31].

$$
N P C=C_{0}+\sum_{t=1}^{n} \frac{C_{t}}{(1+i)^{t}}
$$

689 where $N P C$ is the net-present cost of the system in present day dollars, $C_{0}$ is the upfront cost of 690 the system in present day dollars, $n$ is the number of years being considered for the economic 691 study, $C_{t}$ is the annual operating cost of the system in year $t$ in year $t$ dollars, and $i$ is the overall 692 discount rate used for the analysis. 
694 The upfront cost of the system $\left(C_{0}\right)$ was taken as the sum of the solar panel and the solar panel 695 installation cost. The GSHP and additional HVAC system component costs were not included in 696 the economic analysis because these costs are not directly related to the solar array size, and

697 therefore are not required for comparative purposes. The solar panel unit cost varied depending on

698 the quantity that was ordered, as shown in Figure 12. The installation cost per panel was taken as 699 a constant value at 1.2 times the cost of the solar panels. Both of these costing parameters were 700 based upon a costing estimate from industry, quoted recently in Ontario, Canada.

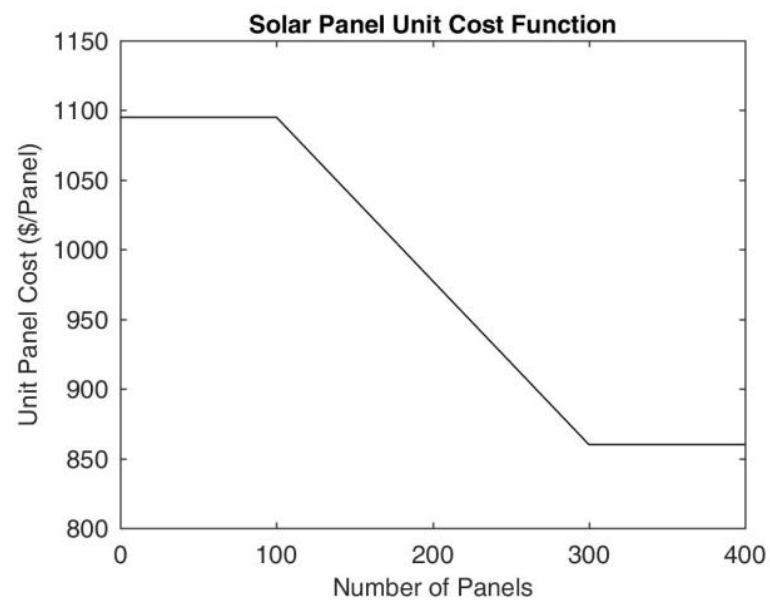

704 The electrical cost used for this study was assumed to be $\$ 0.12$ per $\mathrm{kWh}$. In Ontario, Canada, the 705 average inflation rate from 2012-2016 was 3.36\% [32], but the electric utility rate has a historical 706 growth rate of $4.26 \%$ per year [33]. Therefore, since all of the future costs being considered in this 707 economic study are based upon electric utility costs, these two rates must be combined to determine 708 the overall discount rate for the future costs, as shown in Equation (24).

$$
i=\frac{1+\text { electric utility growth rate }}{1+\text { economic inflation rate }}-1=\frac{1+0.0426}{1+0.0336}-1=0.87 \%
$$


711 An economic assessment using a 20-year system lifetime and 40-year system lifetime was carried

712 out for both the event space and office. The capital costs of solar panels with installation, total heat

713 pump electrical costs, installation NPCs, average installation returns on investment (ROI), and the

714 solar array payback periods are presented in Table 8 for the event space, and

715

716 Table 9 for the office. The electricity consumption of the heat pump was found using Equation

717 (15) as a function of the varying ground temperature, building load, and solar energy collection,

718 which allowed for the economic impact of the combined system to be represented. A plot of the

719 NPC results is also shown in Figure 13.

720

721

Table 8: Event space economic study results summary

\begin{tabular}{|c|c|c|c|c|c|c|c|c|}
\hline & & \multicolumn{3}{|c|}{ 20-Year Lifetime } & \multicolumn{3}{c|}{ 40-Year Lifetime } & \\
\hline $\begin{array}{c}\text { Number } \\
\text { of Solar } \\
\text { Panels }\end{array}$ & $\begin{array}{c}\text { Total } \\
\text { Capital } \\
\text { Cost (\$) }\end{array}$ & $\begin{array}{c}\text { Electrical } \\
\text { Cost } \\
\text { (Today's \$) }\end{array}$ & $\begin{array}{c}\text { Total Net- } \\
\text { Present } \\
\text { Cost } \$ \text { ) }\end{array}$ & $\begin{array}{c}\text { Average } \\
\text { Annual } \\
\text { ROI }\end{array}$ & $\begin{array}{c}\text { Electrical } \\
\text { Cost } \\
\text { (Today's \$) }\end{array}$ & $\begin{array}{c}\text { Total Net- } \\
\text { Present } \\
\text { Cost (\$) }\end{array}$ & $\begin{array}{c}\text { Average } \\
\text { Annual } \\
\text { ROI }\end{array}$ & $\begin{array}{c}\text { Payback } \\
\text { Period } \\
\text { (years) }\end{array}$ \\
\hline 0 & - & $2,035,000$ & $2,035,000$ & N/A & $4,950,000$ & $4,950,000$ & N/A & N/A \\
\hline 100 & 241,000 & $1,524,000$ & $1,765,000$ & $11 \%$ & $3,606,000$ & $3,847,000$ & $14 \%$ & 13 \\
\hline 200 & 430,000 & $1,155,000$ & $1,585,000$ & $10 \%$ & $2,540,000$ & $2,970,000$ & $14 \%$ & 13 \\
\hline 300 & 568,000 & 926,000 & $1,494,000$ & $10 \%$ & $1,891,000$ & $2,459,000$ & $13 \%$ & 13 \\
\hline 400 & 757,000 & 806,000 & $1,563,000$ & $8 \%$ & $1,613,000$ & $2,370,000$ & $11 \%$ & 15 \\
\hline 500 & 946,000 & 747,000 & $1,598,000$ & $7 \%$ & $1,512,000$ & $2,363,000$ & $9 \%$ & 17 \\
\hline 600 & $1,135,000$ & 719,000 & $1,854,000$ & $6 \%$ & $1,472,000$ & $2,607,000$ & $8 \%$ & 19 \\
\hline
\end{tabular}

722

723

724

725

726 


\begin{tabular}{|c|c|c|c|c|c|c|c|c|}
\hline & & \multicolumn{3}{|c|}{ 20-Year Lifetime } & \multicolumn{3}{c|}{ 40-Year Lifetime } & \\
\hline $\begin{array}{c}\text { Number } \\
\text { of Solar } \\
\text { Panels }\end{array}$ & $\begin{array}{c}\text { Total } \\
\text { Capital } \\
\text { Cost (\$) }\end{array}$ & $\begin{array}{c}\text { Electrical } \\
\text { Cost } \\
\text { (Today's \$) }\end{array}$ & $\begin{array}{c}\text { Total Net- } \\
\text { Present } \\
\text { Cost (\$) }\end{array}$ & $\begin{array}{c}\text { Average } \\
\text { Annual } \\
\text { ROI }\end{array}$ & $\begin{array}{c}\text { Electrical } \\
\text { Cost } \\
\text { Today’s \$) }\end{array}$ & $\begin{array}{c}\text { Total Net- } \\
\text { Present } \\
\text { Cost (\$) }\end{array}$ & $\begin{array}{c}\text { Average } \\
\text { Annual } \\
\text { ROI }\end{array}$ & $\begin{array}{c}\text { Payback } \\
\text { Period } \\
\text { (years) }\end{array}$ \\
\hline 0 & - & $3,189,000$ & $3,189,000$ & N/A & $8,938,000$ & $8,938,000$ & N/A & N/A \\
\hline 100 & 241,000 & $2,879,000$ & $3,119,000$ & $6 \%$ & $7,773,000$ & $8,014,000$ & $12 \%$ & 18 \\
\hline 200 & 430,000 & $2,629,000$ & $3,059,000$ & $7 \%$ & $6,767,000$ & $7,197,000$ & $13 \%$ & 18 \\
\hline 300 & 568,000 & $2,429,000$ & $2,997,000$ & $7 \%$ & $5,935,000$ & $6,503,000$ & $13 \%$ & 18 \\
\hline 400 & 757,000 & $2,267,000$ & $3,024,000$ & $6 \%$ & $5,269,000$ & $6,026,000$ & $12 \%$ & 19 \\
\hline 500 & 946,000 & $2,141,000$ & $3,087,000$ & $6 \%$ & $4,756,000$ & $5,702,000$ & $11 \%$ & 20 \\
\hline 600 & $1,135,000$ & $2,044,000$ & $3,179,000$ & $5 \%$ & $4,395,000$ & $5,530,000$ & $10 \%$ & 20 \\
\hline 700 & $1,324,000$ & $1,969,000$ & $3,293,000$ & $5 \%$ & $4,150,000$ & $5,475,000$ & $9 \%$ & 21 \\
\hline 800 & $1,514,000$ & $1,912,000$ & $3,426,000$ & $4 \%$ & $3,992,000$ & $5,506,000$ & $8 \%$ & 22 \\
\hline
\end{tabular}
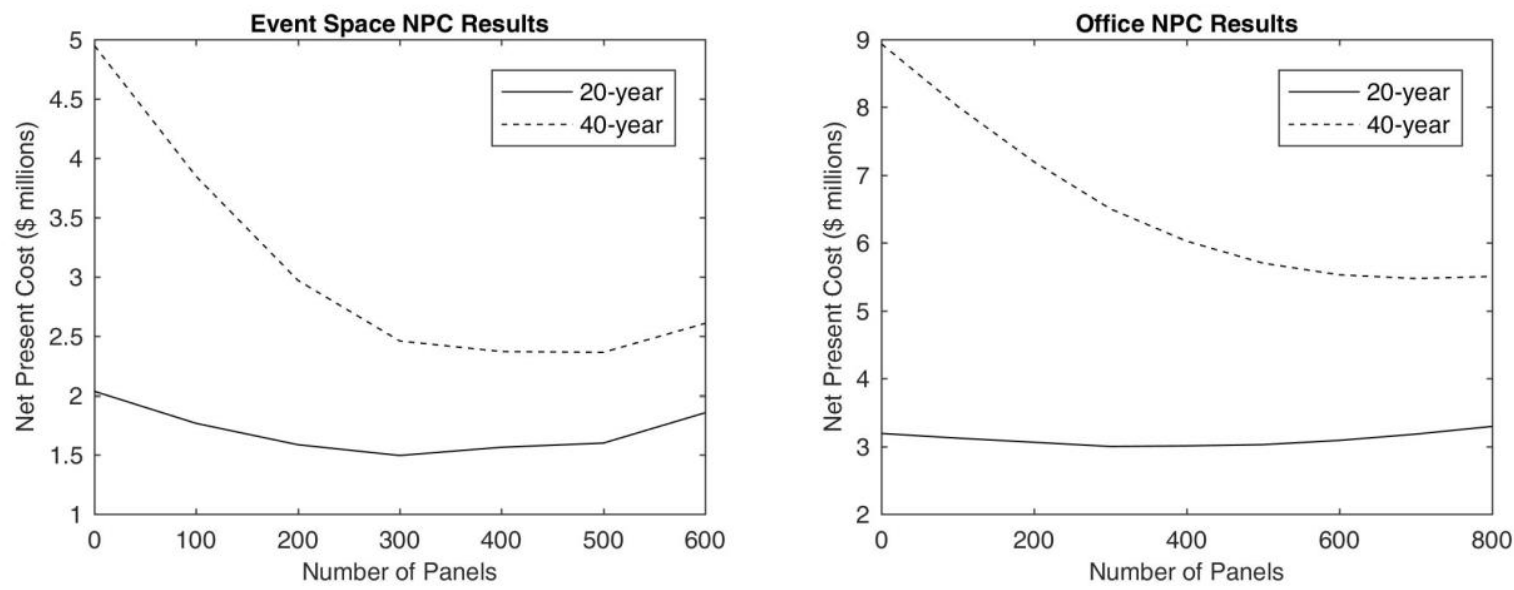

Figure 13: Plot of NPC for the event space and office

731 The economic study results show that as the number of solar panels initially increases, the NPC of

732 the system decreases for both buildings. This decrease occurs because as more solar panels are

733 added, the ground temperature tends to increase over time, which boosts the annual average heating

734 COP of the system. This boost results in a decreased energy consumption, and energy cost, during

735 the heating months. However, as the ground temperature increases, the increasing heating COP

736 effects begin to diminish, and the annual average cooling COP decreases. The solar panels also

737 operate at higher efficiency when lower quantities are used, since the overall system temperatures 
738 are lower than if more panels are used, which also results in additional solar panels exhibiting

739 diminishing benefit for the system.

741 The results of the economic study also show that longer system lifetimes tend to favour a larger

742 number of solar panels compared to shorter system lifetimes, for both buildings. This result occurs

743 because the energy, and therefore cost, savings that are realized due to the addition of more solar

744 panels continues throughout the lifetime of the system. Longer system lifetimes then allow for

745 larger savings from the same initial investment, which results in large solar arrays becoming

746 economical with longer system lifetimes.

748 Lastly, the optimal number of solar panels may be different than the number of panels that results

749 in no long-term ground temperature changes. For example, the event space requires approximately

750200 panels to avoid long-term ground temperature changes, but approximately 500 panels are

751 optimal based on a 40-year NPC analysis. This difference can be attributed to the initial ground

752 temperature in the case study of $10^{\circ} \mathrm{C}$, and a selection of 500 panels resulting in the far-field ground

753 temperature to by $22^{\circ} \mathrm{C}$ over 40 years. In this case, while the temperature rise may be impractically

754 high, this combination of initial ground temperature and temperature rise results in heating

755 performance improvements that offset the reductions in cooling performance, which offsets the

756 cost associated with purchasing additional solar collectors. Therefore, one must consider technical

757 factors such as building load profile, initial ground temperature, and heat pump operation, along

758 with solar panel mounting area, and upfront cost constraints when determining the optimal number

759 of solar panels using the NPC analysis. 


\section{$761 \quad 4 . \quad$ Conclusion}

763 In this study, a model that couples a solar-assisted GSHP system with a simplified ground heat

764 transfer model to determine long-term system performance was presented. The motivation for the

765 study was to develop an approach to determine the number of solar panels required to avoid

766 premature system failure due to ground thermal imbalance, along with determining the economic

767 impact of varying the number of solar panels for a given building and GSHP system. Unlike

768 previous studies in the literature, this study included a thermal mass model to predict ground 769 temperatures over time, as a function of building and solar loads.

771 Initially, a detailed finite element numerical model in COMSOL was used to determine the thermal 772 response of the ground, but because computation times were approximately 5 to 7 hours of wall773 clock time per year simulated, a simplified 4-node thermal mass model was created. This 774 simplified model used calibration data from the detailed model and produced annual energy 775 consumption differences of less than $5 \%$ when compared to the detailed model. Three buildings 776 were investigated for use with the solar-assisted GSHP system, which had heating-to-cooling load

777 ratios of 20.4:1, 8.6:1, and 1.2:1. Simulation results showed that the school, with a load ratio of 778 1.2:1, was not suitable for hybridization because the imbalance factor with no solar panels was 779 less than $10 \%$. However, the results of the energy simulations from the event space and office 780 showed that solar panels were needed to avoid exceeding the maximum imbalance factor of $10 \%$.

781 The event space, which had a heating-to-cooling load ratio of 20.4:1, required approximately 200

782 panels to avoid exceeding the $10 \%$ imbalance factor limit. The office building, which had a 783 heating-to-cooling load ratio of 8.6:1, required approximately 350 panels based upon the same 784 imbalance factor limit. Based upon these results, it was found that the quantity of panels required 
785 for both buildings was a function of both the total building energy consumption, and the building

786 load ratios.

788 An economic analysis was then carried out for both the event space and office building, and the

789 results showed that an optimal number of panels could be found using the presented NPC analysis

790 technique. For the event space, the optimal quantities were 300 panels for a 20 -year system

791 lifetime, and 500 panels for a 40-year system lifetime, which differed from the quantity required

792 based upon the imbalance factor limit. Similarly, the optimal quantities for the office building were

793 found to be 300 and 700 panels for 20-year and 40-year system lifetimes, respectively, which also

794 differed from the quantity determined using the imbalance factor limit. It was determined that these

795 trends were exhibited because as the quantity of solar panels initially increased, the heat pump

796 heating efficiency augmentations from the solar array resulted in decreased total energy

797 consumption, which offset the cost of additional solar panels. However, as the quantity of solar

798 panels continued to increase, and because the efficiency of a solar panel diminishes with increasing

799 operating temperature, solar panel efficiency decreased. Similarly, there is also a reduction in heat

800 pump cooling performance as more solar collectors are added, which also begins to offset the

801 heating performance increases. Therefore, these three factors combine to generate an economically

802 optimal point for a given system.

803

804 Furthermore, this study has shown that solar-assisted GSHP systems need careful attention to 805 ensure that they remain viable from economic and technical viewpoints. Using a simplified ground 806 model with a solar-assisted GSHP system model is a suitable method to determine this viability. 


\section{Acknowledgements}

810 This research was undertaken, in part, thanks to funding from the Canada Research Chairs

811 program. We would also like to acknowledge the Natural Sciences and Engineering Research

812 Council of Canada, and the Ontario Graduate Scholarship program for funding towards this

813 research.

814

\section{Works Cited}

[1] M. Mohanraj, Y. Belyayev, S. Jayaraj and A. Kaltayev, "Research and developments on solar assisted compression heat pump systems - A comprehensive review (Part-B: Applications)," vol. 83, pp. 124-155, 2018.

[2] S. Hu, W. Song, Y. Zhang, D. Pan and T. Meng, "Study of Cold/Hot Stacking Problem Based on Balance Storage of Ground Source Heat Pump," in 2nd International Conference on Computer Engineering and Technology, 2017.

[3] Y. Man, H. Yang and J. Wang, "Study on hybrid ground-coupled heat pump system for airconditioning in hot-weather areas like Hong Kong," Applied Energy, vol. 9, no. 87, pp. 2826-2833, 2010.

[4] J. Meyer, D. Pride, J. O'Toole, C. Craven and V. Spencer, "Ground-Source Heat Pumps in Cold Climates," 31 May 2011. [Online]. Available: http:// www.cchrc.org/sites/default/files/docs/Ground-Source-Heat-Pumps-in-ColdClimates.pdf. [Accessed 24 July 2017].

[5] J. P. Fine, J. Friedman and S. B. Dworkin, "Detailed modeling of a novel photovoltaic thermal cascade heat pump domestic water heating system," Renewable Energy, no. 101, pp. 500-513, 2017.

[6] V. Devabhaktuni, M. Alam, S. Shekara Sreenadh Reddy Depuru, R. C. I. Green, D. Nims and C. Near, "Solar energy: Trends and enabling technologies," Renewable and Sustainable Energy Reviews, no. 19, pp. 555-564, 2013.

[7] M. Mohanraj, Y. Belyayev, S. Jayaraj and A. Kaltayev, "Research and developments on solar assisted compression heat pump systems - A comprehensive review (Part A: Modeling and modifications)," Renewable and Sustainable Energy Reviews, vol. 83, pp. 90-123, 2018.

[8] M. Hawlader, S. Chou and M. Ullah, "The performance of a solar assisted heat pump water heating system.," Applied Thermal Engineering, no. 21, pp. 1049-1065, 2001. 
[9] A. Moreno-Rodriguez, N. Garcia-Hernando, A. Gonzalez-Gil and M. Izquierdo, "Experimental validation of a theoretical model for a direct-expansion solar-assisted heat pump applied to heating," Energy, vol. 60, pp. 242-253, 2013.

[10] Y. Bi, T. Guo, L. Zhang and L. Chen, "Solar and ground source heat-pump system," Applied Energy, no. 78, pp. 231-245, 2004.

[11] D. Lanhua, L. Sufen, D. Lin, L. Xiangli, S. Yan and D. Ming, "Experimental performance analysis of a solar assisted ground source heat pump system under different heating operation modes," Applied Thermal Engineering, vol. 75, pp. 325-333, 2015.

[12] Y. Kuang, R. Wang and L. Yu, "Experimental study on solar assisted heat pump system for heat supply.," Energy Conversion and Management, no. 44, pp. 1089-1098, 2003.

[13] T. You, B. Wang, W. Wu, W. Shi and X. Li, "Performance analysis of hybrid groundcoupled heat pump system with multi-functions," Energy Conversion and Management, no. 92, pp. 47-59, 2015.

[14] G. Emmi, A. Zarrella, M. De Carli and A. Galgaro, "An analysis of solar assisted ground source heat pumps in cold climates," Energy Conversion and Management, no. 106, pp. 660-675, 2015.

[15] N. Zhu, J. Wang and L. Liu, "Performance evaluation before and after solar seasonal storage coupled with ground source heat pump," Energy Conversion and Management, vol. 103, pp. 924-933, 2015.

[16] H. Biglarian, M. Abbaspour and M. H. Saidi, "Evaluation of a transient borehole heat exchanger model in dynamic simulation of a ground source heat pump system," Energy, vol. 147, pp. 81-93, 2018.

[17] H. Biglarian, M. Abbaspour and M. H. Saidi, "A numerical model for transient simulation of borehole heat exchangers," Renewable Energy, vol. 104, pp. 224-237, 2017.

[18] A. Zarrella, G. Emmi and M. De Carli, "A simulation-based analysis of variable flow pumping in ground source heat pump systems with different types of borehole heat exchangers: A case study," Energy Conversion and Management, vol. 131, pp. 135-150, 2017.

[19] M. De Carli, M. Tonon, A. Zarrella and R. Zecchin, "A computational capacity resistance model (CaRM) for vertical ground-coupled heat exchangers," Renewable Energy, vol. 35, pp. 1537-1550, 2010.

[20] S. J. Rees, "An extended two-dimensional borehole heat exchanger model for simulation of short and medium timescale thermal response," Renewable Energy, vol. 83, pp. 518526, 2015.

[21] L. Pu, D. Qi, K. Li, H. Tan and Y. Li, "Simulation study on the thermal performance of vertical U-tube heat exchangers for ground source heat pump system," Applied Thermal Engineering, vol. 79, pp. 202-213, 2015.

[22] Y. L. E. Law and S. B. Dworkin, "Characterization of the effects of borehole configuration and interference with long term ground temperature modelling of ground source heat pumps," Applied Energy, no. 179, pp. 1032-1047, 2016.

[23] COMSOL Inc., "COMSOL Multiphysics," 2017. [Online]. Available: www.comsol.com. 
[24] O. Ozgener and L. Ozgener, "Modeling of driveway as a solar collector for improving efficiency of solar assisted geothermal heat pump system: a case study," Renewable and Sustainable Energy Reviews, no. 46, pp. 210-217, 2015.

[25] M. A. Lambert and A. Beyene, "Thermo-economic analysis of solar powered adsorption heat pump," Applied Thermal Engineering, no. 27, pp. 1593-1611, 2007.

[26] J. P. Fine, J. Friedman and S. B. Dworkin, "Transient analysis of a photovoltaic thermal heat input process with thermal storage," Appied Energy, vol. 160, pp. 308-320, 2015.

[27] Y. A. Çengel and A. J. Ghajar, Heat and mass transfer: fundamentals and applications, New York: McGraw-Hill, 2011.

[28] S. Lazzari, A. Priarone and E. Zanchini, "Long-term performance of BHE (borehole heat exchanger) fields with negligible groundwater movement," Energy, vol. 35, pp. 49664974, 2010.

[29] Multistack, "Multistack Water to Water Heat Pump Catalog for R410 or R134a Refrigerant," 2017. [Online]. Available:

https://www.google.ca/url?sa=t\&rct=j\&q=\&esrc=s\&source=web\&cd=2\&cad=rja\&uact=8 \&ved=0ahUKEwjnx7HDpbbVAhUC04MKHZKJD58QFgg6MAE\&url=http\%3A\%2F\%2Fwww. multistack.com\%2FPortals\%2F0\%2FLiterature\%2FCatalogs\%2FWater\%2520To\%2520Wat er\%2520Heat\%2520Pump\%2520Catalog.pdf\&usg=AFQjCNG5NPVgFz-hr6aShgoqsOe5VSHQg. [Accessed 21 May 2017].

[30] Meteorological Service of Canada and The National Research Council of Canada, "Canadian Weather Energy and Engineering Data Sets (CWEEDS Files)," The National Research Council of Canada, Ottawa, 2008.

[31] D. G. Newnan, J. P. Lavelle and T. G. Eschenbach, Engineering Economic Analysis (10th Edition)., Oxford University Press, 2009.

[32] Statistics Canada, "Consumer Price Index, by province (Ontario)," Government of Canada, 20 January 2017. [Online]. Available: http://www.statcan.gc.ca/tables-tableaux/sumsom/l01/cst01/econ09g-eng.htm. [Accessed 2 August 2017].

[33] D. D. Dewees, "Background Report: What Is Happening to Ontario Electricity Prices?," University of Ottawa, Ottawa.

[34] ISO, "Solar energy-Solar thermal collectors-Test methods ISO/FDIS 9806:2013(E)," Geneva, 2013.

[35] Aermec, "Aermec NRL Chiller Datasheet," Aermec S.p.A, Rome, Italy.

[36] E. Bellos, C. Tzivanidis, K. Moschos and K. A. Antonopoulos, "Energetic and financial evaluation of solar assisted heat pump space heating systems," Energy Conversion and Management, vol. 120, pp. 306-319, 2016.

[37] S. Gehlin, "Thermal response test - Method development and evaluation - PhD Thesis," Luleå University of Technology, 2002.

[38] H. Carslaw and J. Jaeger, Conduction of Heat in Solids, Oxford University Press: Oxford, 1959. 
[39] S. Javed and P. Fahlen, "Thermal Response Testing of a Multiple Borehole Ground Heat Exchanger," in SET2010 - 9 th International Conference on Sustainable Energy Technologies, Shanghai, 2010.

[40] R. A. Beier, M. D. Smith and J. D. Spitler, "Reference data sets for vertical borehole ground heat exchanger models and thermal response test analysis," Geothermics, vol. 40, pp. 79-85, 2011.

816 